\title{
Local Enhancement of Extreme Precipitation during Atmospheric Rivers as Simulated in a Regional Climate Model
}

\author{
RAQUEL LORENTE-PLAZAS \\ School of STEM, University of Washington Bothell, Bothell, Washington, and Department of Physics, \\ Universidad de Murcia, Murcia, Spain \\ TODD P. MITCHELL \\ Joint Institute for the Study of the Atmosphere and Ocean, University of Washington, Seattle, Washington \\ Guillaume MAuger \\ Climate Impacts Group, University of Washington, Seattle, Washington \\ ERIC P. SALATHÉ JR. \\ School of STEM, University of Washington Bothell, Bothell, Washington
}

(Manuscript received 28 December 2017, in final form 26 June 2018)

\begin{abstract}
This paper examines the synoptic conditions that yield extreme precipitation in two regions with different orographic features, the Olympic Mountains and Puget Sound. To capture orographic extreme precipitation, a dynamical downscaling is performed, driven by the NCEP-NCAR reanalysis and evaluated for cool-season months from 1970 to 2010 . Clustering techniques are applied to the regional climate simulation, which reveals the Olympic Mountains and Puget Sound as regions with distinct temporal variability in precipitation. Results show that approximately one-third of the extreme precipitation events in each region occur without a similarly extreme event in the other, in spite of the fact that the two areas are very closely located and one is downstream of the other. Composites of synoptic conditions for extreme precipitation events show differences in integrated vapor transport (IVT) due to its dynamical component (winds at $850 \mathrm{hPa}$ ) and its thermodynamical component [integrated water vapor (IWV)]. For Puget Sound events, IVT is lower compared to Olympic Mountain events because of lower wind speeds. Olympic Mountain events have lower IVT compared to events with extreme precipitation in both regions, but in this case, the difference is due to lower IWV and more southerly winds. These differences in the large-scale conditions promote differences in the mesoscale mechanisms that enhance precipitation in each location. For Puget Sound events, static stability is higher, and there is a weak rain shadow. For Olympic Mountain events, static stability is lower, and a strong rain shadow is present. During extreme events in both regions, orographic modulation is minimized and large-scale effects dominate.
\end{abstract}

\section{Introduction}

Global mean extreme precipitation is predicted to increase at about the same rate as global mean atmospheric water vapor (Allen and Ingram 2002; Trenberth et al. 2003), that is, at about $7.5 \%$ per degree Celsius warming, following the Clausius-Clapeyron equation (Held and Soden 2006; O'Gorman and Schneider 2009). Total precipitation, by contrast, is limited by the global energy

Corresponding author: Raquel Lorente-Plazas, lorente.plazas@ gmail.com budget and is projected to increase more slowly. At the regional scale, attributions of regional-local extreme precipitation to the warming climate involve several uncertainties. To understand the effects of climate on extreme events at the local scale, it is essential to establish the connections between the projected climate change and changes in the frequency and intensity of precipitation.

Atmospheric rivers (ARs) are an important large-scale driver of heavy precipitation that both leads to floods and produces valuable water supply (Paltan et al. 2017). The AR concept was proposed by Zhu and Newell (1998) and it refers to narrow elongated regions of high water vapor 
concentration. ARs are typically located within the warm sector of midlatitude storms over the ocean and affect many worldwide regions such as Europe (Sodemann and Stohl 2013; Lavers and Villarini 2013; Eiras-Barca et al. 2016), western South America (Viale and Nuñez 2011), East Asia (Kamae et al. 2017), and western North America (Ralph et al. 2006; Dettinger 2011; Neiman et al. 2011). ARs are key to the study of water vapor transport in extratropical regions. These filaments cross the midlatitudes from the subtropics or tropics toward higher latitudes and account for $90 \%$ of meridional water vapor transport (Zhu and Newell 1998). AR water vapor flux typically occurs within the warm conveyor belt of extratropical cyclones. Although not a focus of the current study, Neiman et al. (2008) showed that for weaker northeast Pacific ARs in summer, the maximum in water vapor flux can instead be located behind the cold front. Even when occurring in the warm conveyor belt, the water vapor flux may not necessarily coincide with the low-level jet (Eiras-Barca et al. 2017), as is often assumed (Gimeno et al. 2014). Regardless of their location, a key feature of ARs is the narrow band of high water vapor concentration that is closely coupled to the dynamics of midlatitude storms.

Considering the relevance of the ARs, several studies have been focused on AR detection, and some of these methods were reviewed by Gimeno et al. (2014). The integrated vapor transport (IVT) that integrates wind direction and specific humidity is often used to detect ARs (Wick et al. 2013a). Although the overall presence of ARs is well forecasted, numerical weather models still poorly represent the position of the landfalling ARs, and the largest quantitative precipitation forecast errors are associated with this inaccuracy (Ralph et al. 2010; Wick et al. 2013b). One gap in the understanding of the ARs is how mesoscale features of ARs are affected by complex terrain.

The intensity and direction where ARs impact the coast can strongly modulate the location of precipitation (Ralph et al. 2016). Several studies have shown that coastal precipitation over western South and North America is greatly enhanced by the interaction of incoming integrated vapor transport with local orography (Ralph et al. 2006; Viale and Nuñez 2011; Ralph et al. 2013). This same mechanism drives intense precipitation over different continental regions because of its interaction with topography (e.g., Stohl et al. 2008; Lavers and Villarini 2013; Ramos et al. 2015). In addition to low-level moisture and IVT, tropospheric stability and wind shear have an important effect on the intensity and spatial distribution of orographically induced precipitation (Kirshbaum and Durran 2004).

In spite of their coarse resolution, global climate models (GCMs) are able to represent ARs since they are driven by synoptic-scale winds and vapor transport (Warner et al. 2015; Ramos et al. 2015). However, GCMs (including reanalysis products) are inadequate for assessing extreme precipitation at regional and local scales because of the coarse resolution of terrain features and other mesoscale effects (Dulière et al. 2011; Feser et al. 2011; Di Luca et al. 2012). In particular, these models poorly capture regional precipitation frequency, intensity, and spatial variability. Regional climate models (RCMs) represent local-scale weather by refining the spatial resolution over a limited area, providing more orographic details, and parameterizing subgrid physical processes. As a result, RCMs are able to simulate features, such as orographic precipitation, land-sea breezes, rain shadows, and wind storms, and consequently reproduce observed extreme precipitation processes and events better than coarse global models.

The complex terrain of the U.S. Pacific Northwest includes mountain ranges and land-sea contrasts that make it challenging to study the extreme precipitation. In this midlatitude region, the prevailing winds are westerly, and rain shadows are associated with mountain ranges that are primarily oriented north-south. Siler et al. (2013) found that $70 \%$ of the interannual variability in the wintertime rain-shadow effect could be explained by fluctuations in the large-scale atmospheric circulation. The passage of warm or occluded fronts drives strong temperature advection over the mountains, creating precipitation events with a weak rain shadow.

This study aims to document the interplay of the orography and large-scale weather on RCM simulations of heavy precipitation by focusing on two adjacent regions with different topography: the Olympic Mountains and Puget Sound of the Pacific Northwest. The western slopes of the Olympics are the wettest place in the 48 contiguous states. The western slopes are separated from the Pacific Ocean by a $20-35-\mathrm{km}$-wide Pacific Ocean coastal plain, with the Olympic massif extending almost $100 \mathrm{~km}$ across the center of the Olympic Peninsula, and rising to their highest peak at $2427 \mathrm{~m}$. Puget Sound is a complex estuarine system of interconnected marine waterways and basins between the Olympic Mountains to the west and the Cascade Range to the east.

The analysis employs an upscaling technique by identifying extreme precipitation events over the finestresolution RCM grid and associating these events to large-scale weather patterns simulated on the outermost coarse-resolution grid. The manuscript is organized as follows. The regional climate simulation and methods are described in section 2. Section 3 shows the results. The main conclusion are summarized in section 4 .

\section{Data and methods}

To associate the local extreme precipitation to largescale patterns, a regional climate simulation is performed 
and clustering methods are applied to the modeled precipitation. The dynamical downscaling from the reanalysis is needed to better represent the local orographic and coastline effects, along with the associated intense precipitation processes.

The period to be analyzed is $1970-2010$ for a total of 40 wet seasons. The 6-month cool-season period from October to March is analyzed, since these months are the rainiest in the Pacific Northwest and the dominant season for flood-producing precipitation events.

\section{a. Regional climate simulations}

The regional climate simulation was conducted with the Weather Research and Forecasting (WRF; Skamarock et al. 2008) Model, which is a nonhydrostatic and mesoscale numerical weather model. In this work, WRF, version 3.1.1, was used. We acknowledge this is an old model version, but this simulation is used since it has been validated and analyzed in previous works (e.g., Dulière et al. 2011). Also, this version is still used in other works (e.g., Rasmussen et al. 2014; Minder et al. 2018). Initial and boundary conditions are provided by the NCEP-NCAR reanalysis project with a spatial resolution of a $2.5^{\circ}$ latitude-longitude grid (Kalnay et al. 1996). The simulation covered the 40-yr period from 1970 to 2010. The lateral boundary conditions and the sea surface temperature (SST) were updated every $6 \mathrm{~h}$. Although simulation outputs were every $6 \mathrm{~h}$, daily mean values were used in this analysis since previous research shows that this time scale is adequate for detecting AR events (Warner et al. 2015).

WRF was set up by using two nested domains (Fig. 1). The outer domain, at $36-\mathrm{km}$ resolution, covers the western North American continent and much of the eastern Pacific Ocean in order to capture the large-scale dynamics governing weather in the U.S. Pacific Northwest. The inner domain at $12-\mathrm{km}$ resolution focuses on the U.S. Pacific Northwest region itself. Thirty vertical levels were used in the model spanning from the surface to $10 \mathrm{hPa}$ with the highest resolution in the boundary layer. Oneway nesting was applied in this study. WRF runs were initialized 15 months before the simulation period as spinup. The physics parameterizations for microphysics, cumulus parameterization, planetary boundary layer, land surface models, and longwave and shortwave radiation are summarized in Table 1.

The skill of this simulation to represent extreme events was validated by Dulière et al. (2011), where it is shown that extreme precipitation indices are highly correlated with the observations provided by the Historical Climatology Network in eastern Washington State. As additional validation, here we have focused on the target regions of this study. The simulated mean regional series for the Olympic Mountain and Puget
Sound regions are compared against the observations at Forks and Mount Vernon, respectively, using the Cooperative Observer Program (COOP) dataset provided by NOAA's National Centers for Environmental Information. The results show the simulation closely follows the observations, but it overestimates precipitation for mean (0.30 at the Olympic Mountains and 0.95 at Puget Sound) and extreme values using the 95th percentile (1.81 at the Olympic Mountains and 0.39 at Puget Sound). Also, better temporal correlation is found for observations at the Olympic Mountains $(r=0.78)$ than Puget Sound $(r=0.60)$.

\section{b. Regionalization approaches}

Clustering analysis (CLA) and principal component analysis (PCA) are applied to identify regions with coherent temporal precipitation variability within the model domain. Similar approaches have been applied before to other variables such as winds (e.g., Jiménez et al. 2008; Lorente-Plazas et al. 2015). The regionalization approach is as follows.

First, an S-mode (spatial mode) PCA (Richman 1986; von Storch and Zwiers 1999) is applied to the time series of mean daily precipitation. The S-mode identifies time series with similar temporal variability in the domain. The covariance matrix is used in order to better capture the magnitude of the extreme events in addition to the temporal variability. Second, CLA is applied to a subset of the principal component loadings (map patterns), which are also called empirical orthogonal functions (EOFs). The scree plot test (Cattell 1966) is used to choose the number of retained EOFs according to the percentage of explained variance. By applying the CLA to the retained modes instead of directly to the time series, we reduce some noise due to local effects that could impede the clustering. The impact of using more or less EOFs on the regionalization is assessed in the following section.

CLA groups similar objects according to a distance metric. The objects here are the daily precipitation temporal series at each grid point. The Euclidean distance is used to calculate a matrix of distances whose elements $d_{i j}$ are given by

$$
d_{i j}=\frac{1}{M} \sqrt{\sum_{k=1}^{M}\left[e_{k}\left(x_{i}\right)-e_{k}\left(x_{j}\right)\right]^{2}},
$$

where $e_{k}(x)$ is the value of the $k$ th retained eigenvectors at grid point $x$, including all $M$ retained EOFs according to the scree plot test. The distance $d_{i j}$ represents the similarity between two precipitation time series at the grid points $x_{i}$ and $x_{j}$. Lower values of $d_{i j}$ indicate similar temporal variability between the precipitation time series at $x_{i}$ and $x_{j}$, and these time series will belong to the same cluster. 


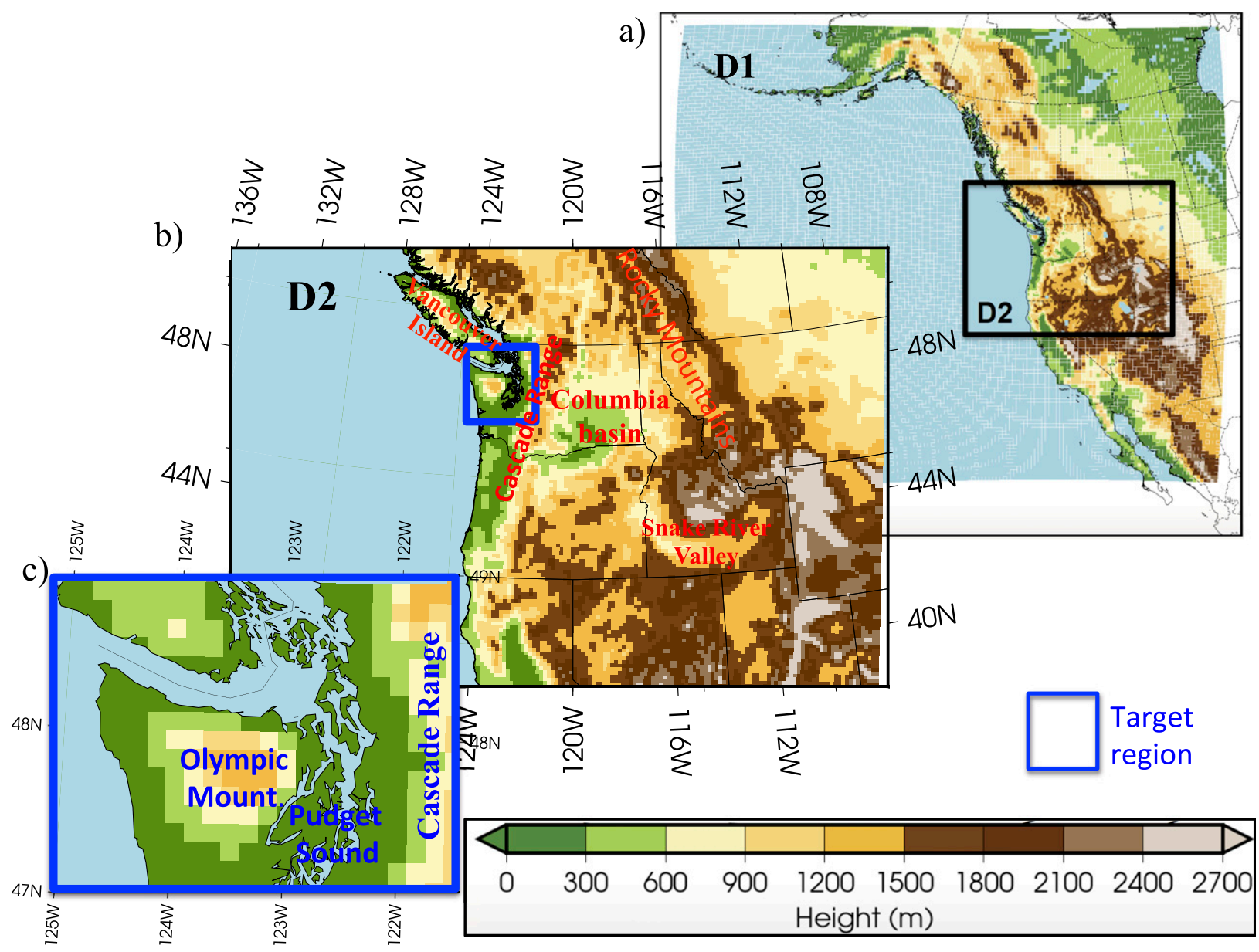

FIG. 1. Domain configuration for the regional climate simulation. (a) The two nested domains: the inner (D2) and outer (D1) domains with 12- and 36-km spatial resolution, respectively. (b) Inner domain with the main orographic features highlighted in red; the blue square depicts the target region. (c) Zoom-in of the target region. Colors depict the model terrain height for the simulation.

A two-stage CLA algorithm combining hierarchical and nonhierarchical algorithms (Kaufmann and Weber 1996) is carried out. Hierarchical CLA using Ward's minimum variance (Ward 1963) provides the centroids of the first-guess cluster, which are used as initial seeds for the $k$-means nonhierarchical method (Wilks 1995). These methods are applied to the retained modes using the distance metric described in Eq. (1).
The appropriate number of clusters that Ward's method provides to the $k$-means method is selected by analyzing the value of the distance measure at which the two most similar clusters merge in each step. When the distance after merging two potential clusters is large, then two very different clusters have been merged. This result is an indication to stop the algorithm at the previous step. Once the centroids are obtained, they are

TABLE 1. Physical schemes used in the model configuration.

\begin{tabular}{lll}
\hline \multicolumn{1}{c}{ Scheme } & \multicolumn{1}{c}{ Name } & \multicolumn{1}{c}{ References } \\
\hline Longwave/shortwave radiation & CAM & Mlawer et al. (1997) \\
Boundary layer & Yonsei University (YSU) & Hong et al. (2006) \\
Cumulus & Kain-Fritsch & Kain (2004) \\
Land surface & Noah & Chen and Dudhia (2001) \\
Surface layer & MM5 similarity (original version) & Jiménez et al. (2012) \\
Microphysics & Thompson & Thompson et al. (2008) \\
\hline
\end{tabular}


a)

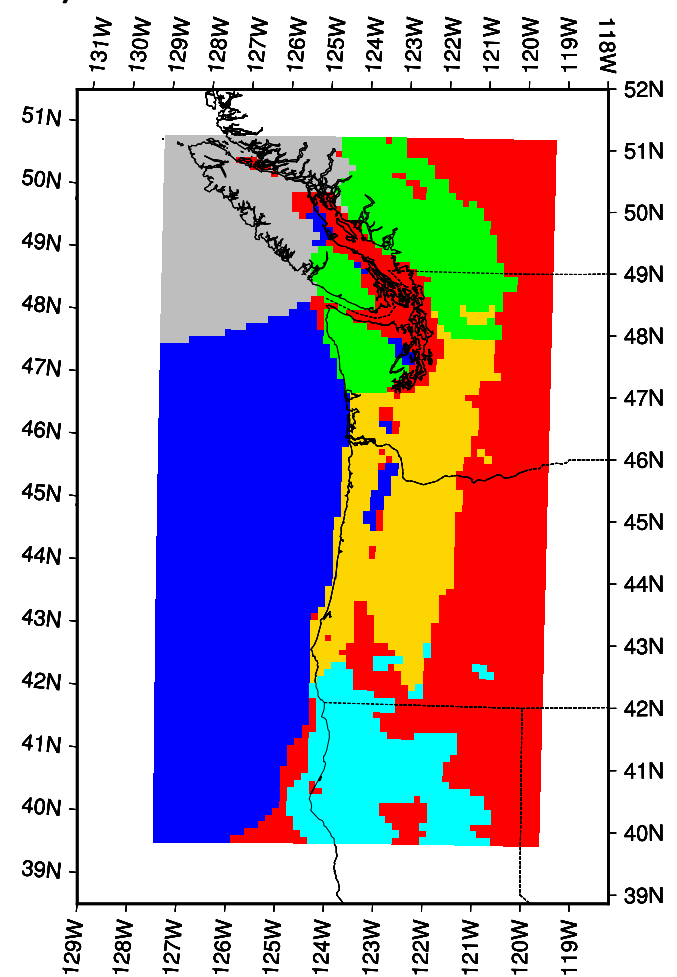

b)

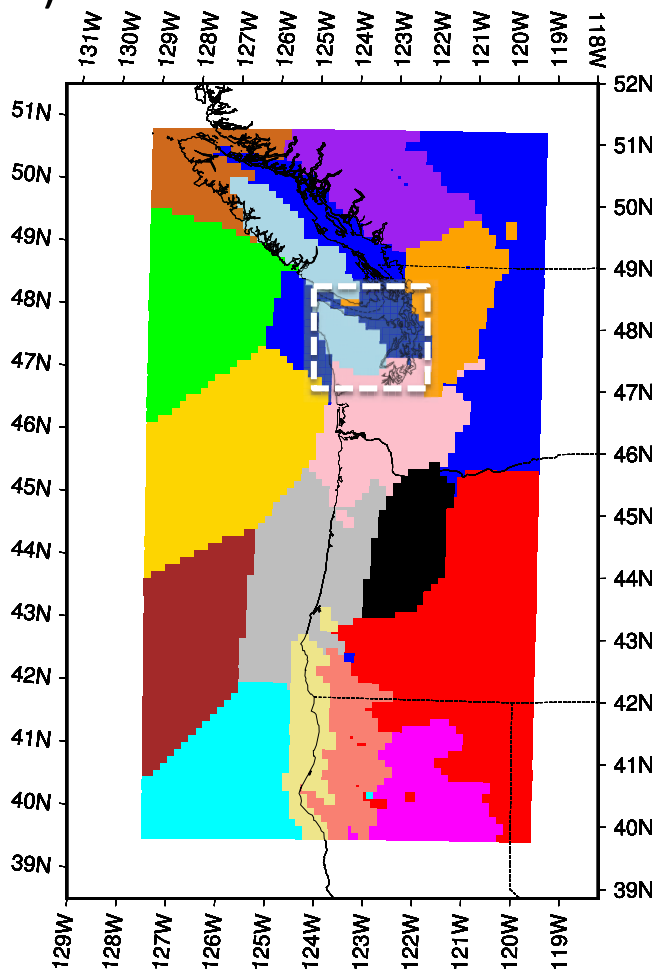

FIG. 2. Regions with different temporal variability obtained in the clustering analysis using daily precipitation for October-March, 1970-2010. Clustering methods are applied to (a) 5 EOFs obtaining 6 regions and (b) 20 EOFs obtaining 16 regions. The white rectangle shows the focus region for this study.

used as seeds in a subsequent application of the nonhierarchical clustering procedure.

The regionalization is performed over the western part of the 12-km domain (defined by the crest of the Cascade Range; Fig. 2) in order to reduce computational time and because of ambiguity about the role of ARs and the ability of the model to accurately represent them in the eastern part of the domain.

We have experimented with different choices in the clustering and have found the regions discussed here are robust. As an example, results for 5 and $20 \mathrm{EOFs}$ are shown below as well as results based on an independent approach: empirical orthogonal teleconnection (EOT; Van den Dool et al. 2000) analysis.

EOT analysis can also be used to identify regions with coherent variability. The approach works by first identifying the point that correlates best with every other point in the domain. The correlation of each grid cell with this time series is the first EOT (EOT1). This time series is then linearly regressed from the dataset to produce a residual dataset, and the analysis is repeated on the residual dataset to find additional unique time series and associated correlation patterns. The EOTs, by construction, are temporally orthogonal, but the spatial patterns can overlap.

\section{c. Extreme precipitation events and associated large-scale circulation}

We construct a single time series of daily cool-season (October-March) precipitation for the Olympic Mountain and Puget Sound regions by averaging over all grid cells in each region for the full 40-yr WRF simulation (1970-2010). Since these regions are identified through the cluster analysis, the regional time series are generally well correlated across each of the grid cells in the region. The extreme precipitation events are identified according to the 95th percentile of the regional mean series, and days with precipitation that exceed this threshold are hereafter referred to as "extreme events" (e.g., Allan and Soden 2008; Peterson et al. 2008). Similar results were obtained with a more restrictive threshold of the 99th percentile.

To analyze the relationship of the extreme precipitation with the ARs, the IVT, the integrated water vapor (IWV), and 850-hPa winds are analyzed on the outer $36-\mathrm{km}$ domain. The IVT is computed as follows: 

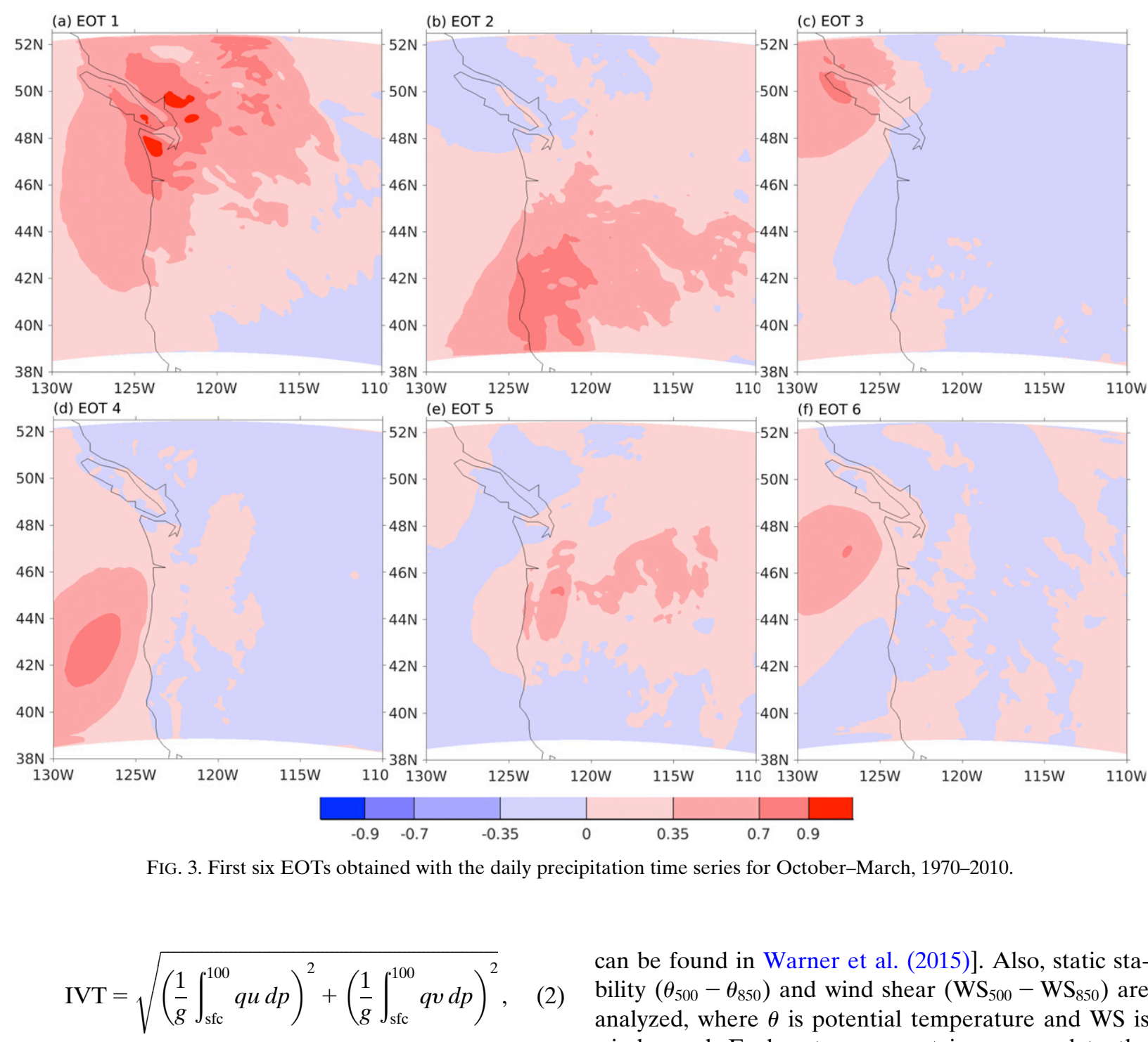

where $q$ is the specific humidity $\left(\mathrm{kg} \mathrm{kg}^{-1}\right), u$ and $v$ are zonal and meridional winds $\left(\mathrm{m} \mathrm{s}^{-1}\right), g$ is the acceleration due to gravity $\left(\mathrm{m} \mathrm{s}^{-2}\right)$, and $d p$ is the differential of the pressure. Here, $d p$ is computed as the difference between two adjacent pressure levels $(\mathrm{hPa})$ and the integrated IVT is computed as the sum along these discrete pressure increments. IVT is integrated from surface to $100 \mathrm{hPa}$ since around $75 \%$ of water vapor transport occurs in the lowest $2.5 \mathrm{~km}$ of the atmosphere (Ralph et al. 2005). The two IVT components - the thermodynamics component, IWV, and the dynamics component, 850-hPa winds-are assessed. Winds are analyzed at $850 \mathrm{hPa}$ because 1) it is the typical level where ARs intersect with the upper slopes of major terrain barriers in the western United States, 2) this is the same level used to track relative vorticity in extratropical cyclones, and 3) this height wind closely matches aircraftobserved winds under AR conditions [wider justification

can be found in Warner et al. (2015)]. Also, static stability $\left(\theta_{500}-\theta_{850}\right)$ and wind shear $\left(\mathrm{WS}_{500}-\mathrm{WS}_{850}\right)$ are analyzed, where $\theta$ is potential temperature and WS is wind speed. Each extreme event is compared to the 40-yr climatology, and anomalies from the climatology for each event are averaged to create an anomaly composite. Anomalies are computed as seasonal mean (October-March) minus extreme precipitation events at Puget Sound, the Olympic Mountains, or both regions (Common events).

\section{Results}

\section{a. Regions with different precipitation variability}

In this work, the clustering method is applied to a distance matrix that involves the EOFs. Figure 2 shows the regions obtained by CLA using 5 EOFs and 20 EOFs. Each color represents a region with coherent temporal variability of daily precipitation. Increasing the number of EOFs in the distance matrix metric increases the degrees of spatial variability and results in a 

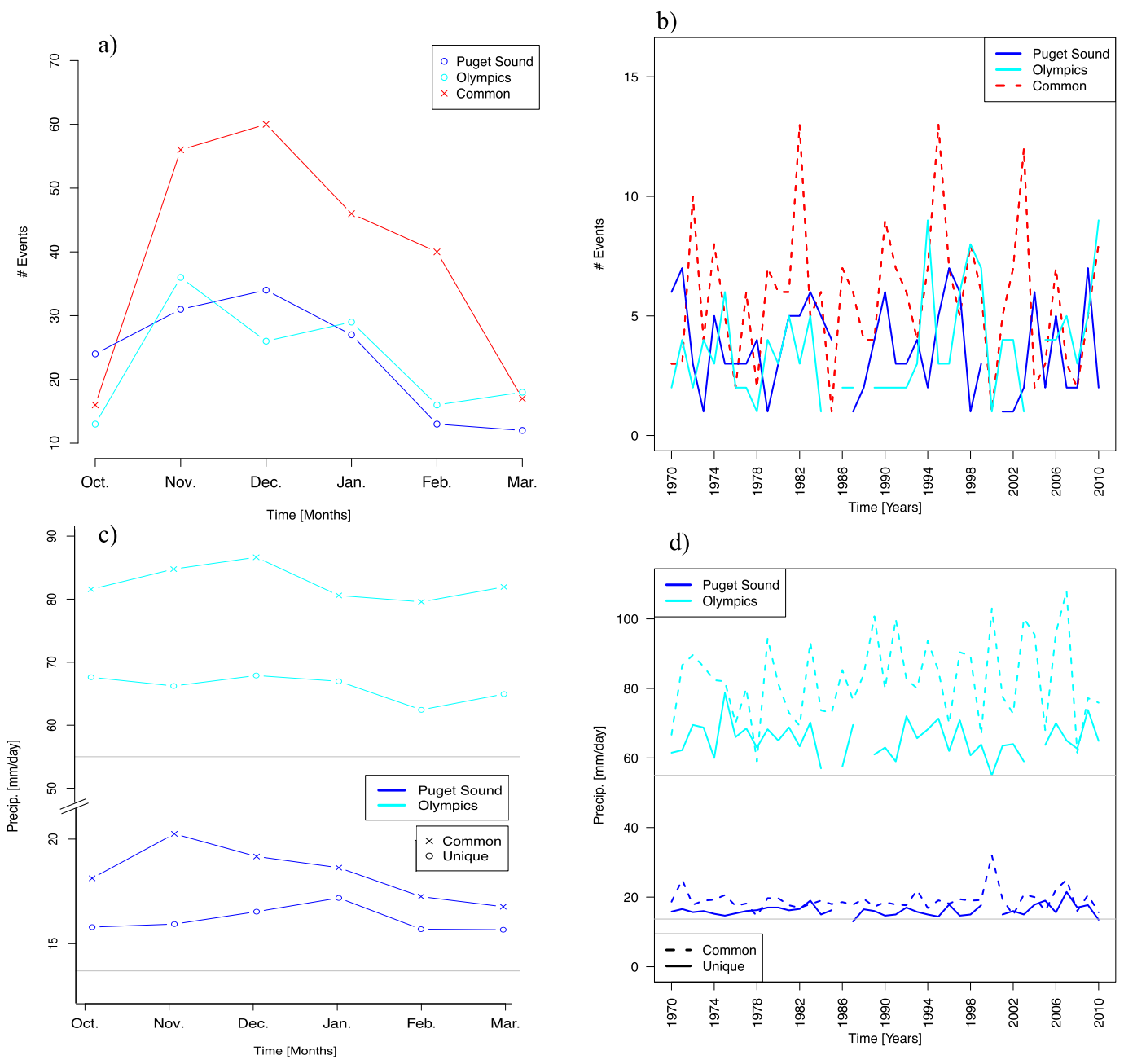

d)

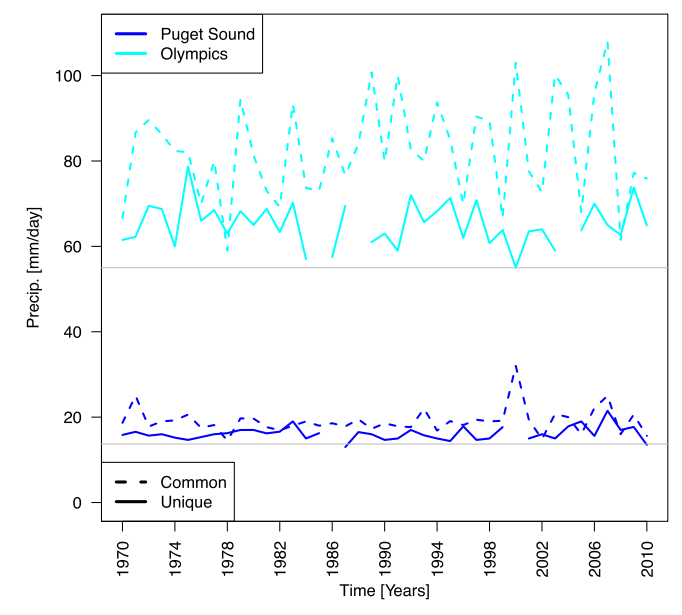

FIG. 4. Interannual and seasonal variations in extreme precipitation for events occurring in Puget Sound, the Olympic Mountains, and when both regions encounter heavy rains on the same day. (a) The total number of extreme events for each month from 1970 to 2010, (b) the number of extreme events per year, (c) the 1970-2010 average extreme precipitation intensity for each month, and (d) annual averages of extreme precipitation. The 95th percentiles in daily precipitation, for 1970-2010, are indicated by the horizontal gray lines in (c).

greater number of unique precipitation clusters. When the CLA is applied with 5 EOFs (Fig. 2a), 6 regions with different precipitation behavior are identified. When the number of retained EOFs increases to 20 (Fig. 2b), the number of regions increases to 16.

With only 6 regions, precipitation variability over the land area is partitioned essentially by latitude over the coastal and Cascade Mountains. A broad region (Fig. 2a, red) indicates regions that do not share this strong orographic connection. By increasing the number of clusters, we find that inland regions are more closely related to the orography, and the regions in the 20-EOF solution (Fig. 2b) subdivide the larger 5-EOF regions. For instance, the cluster east of the Cascades (red region Fig. 2a) is divided into two regions. The Cascades and areas to the west of the Cascades (yellow region) are divided into 4 new regions. The region that includes the Canadian Coast Range, Vancouver Island Range, and the Olympic Mountains (green) are split. Also, three clusters are formed in the Northern California (turquoise) region, splitting the region into three north-south strips associated with the complex terrain. Note how the two offshore regions in Fig. 2a are also divided into several clusters, which denotes the spatial variability of the precipitation over the ocean.

Both regionalizations, with 5 EOFs and 20 EOFs, distinguish the different precipitation variability of the Olympic Mountain and Puget Sound regions. To illustrate the value of the clustering method to isolate important regional differences, we will focus on the region highlighted with a white rectangle in Fig. $2 b$. While one could select areas to compare based on subjective 

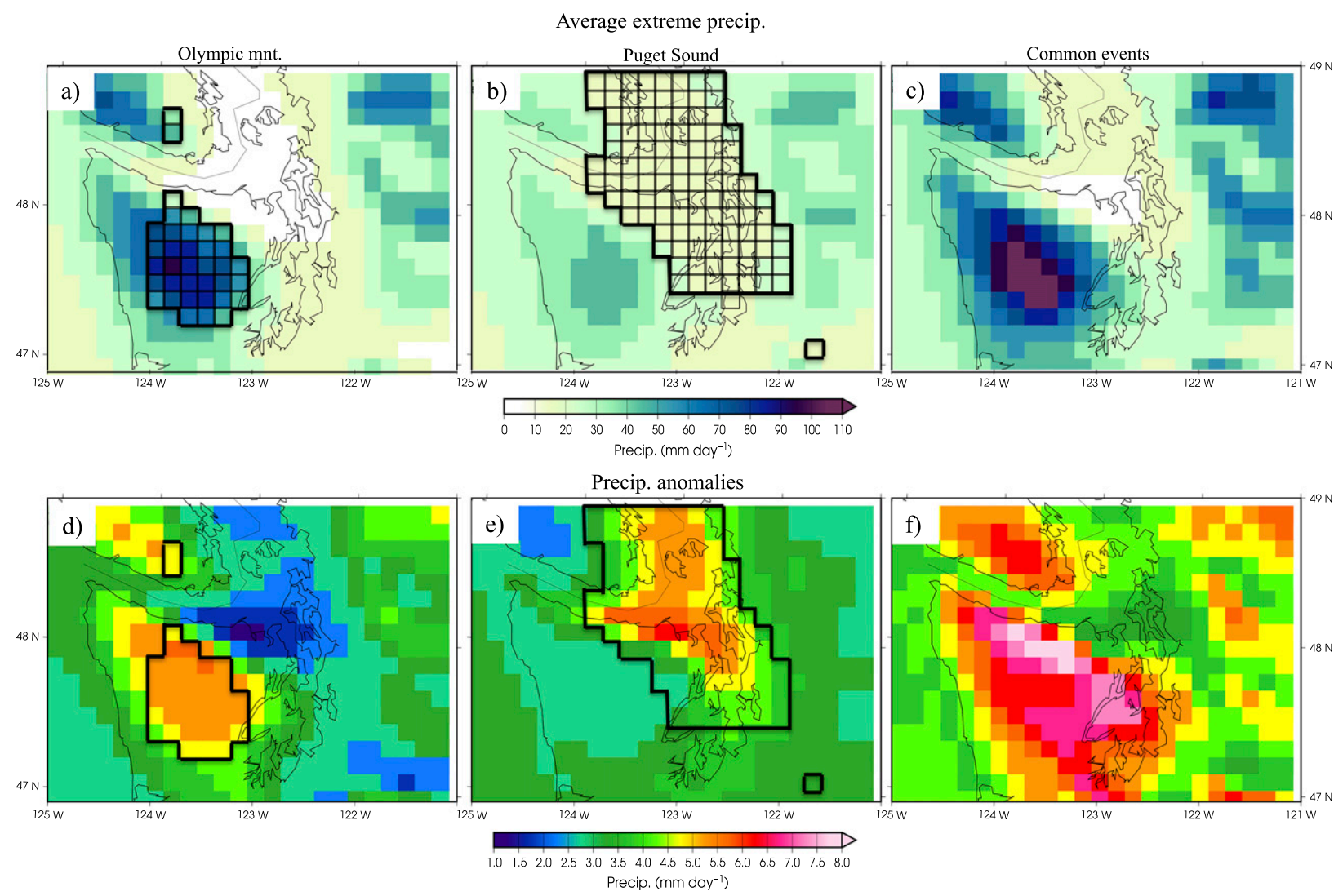

FIG. 5. (top) Average extreme precipitation and (bottom) anomalies relative to the 1970-2010 average for extreme events occurring in the (a),(d) Olympic Mountains, (b),(e) Puget Sound region, and (c),(f) both regions on the same day. Black polygons highlight the grid cells that were used to define the Olympic Mountain region in (a) and (d) and the Puget Sound region in (b) and (e).

considerations, the clustering techniques provide a more objective procedure to separate the model grid points from the Olympic Mountains and Puget Sound and clearly delineate the different precipitation processes in these two locations.

As an independent check on the CLA analysis, we compare the results with those from EOT. Figure 3 shows the temporal correlation of the simulated precipitation at each grid cell with the first six EOTs. In comparing the 6-region CLA (Fig. 2a) and EOT results (Fig. 3), we see that the two methods reveal essentially the same geographical structure. EOT1 corresponds to the green region in Fig. 2a, EOT2 corresponds to the cyan region, EOT3 corresponds to the gray region, and EOT5 corresponds to the gold region. EOTs 4 and 6 correspond to precipitation variability over ocean (blue region in Fig. 2a). The close correspondence confirms that the features identified in the CLA analysis are robust.

\section{b. Extreme precipitation events}

Two regional mean series of precipitation are computed by averaging the time series at 117 grid cells for the Puget
Sound region and 80 grid cells for the Olympic Mountains (depicted as black squares in Fig. 5). From these two time series, we can select the dates and magnitudes of the top $5 \%$ daily winter (March-October) precipitation events, that is, the 375 days with heaviest precipitation in each region. The 95th percentile precipitation is $13.7 \mathrm{~mm} \mathrm{day}^{-1}$ for Puget Sound and $55.0 \mathrm{~mm} \mathrm{day}^{-1}$ for the Olympic Mountains. Of these events, 235 or $63 \%$ occurred simultaneously in both regions (hereafter termed "Common events"); 140 events $(37 \%)$ were unique to each region (hereafter referred to as either Puget Sound or Olympic Mountain events).

The interannual variability of extreme precipitation over the period of the simulation does not show a clear trend in the annual mean extreme precipitation values (Fig. 4d) nor in the number of extreme events (Fig. 4b). During the simulated period, the highest annual mean extreme precipitation was in 2007 with $108 \mathrm{~mm} \mathrm{day}^{-1}$ for the Olympic region $\left(25 \mathrm{~mm} \mathrm{day}^{-1}\right.$ in Puget Sound) and in 2000 with $32 \mathrm{~mm} \mathrm{day}^{-1}$ for the Puget Sound region (103 $\mathrm{mm} \mathrm{day}^{-1}$ in the Olympic Mountains). There are no extreme events simulated exclusively for Puget Sound during 1986 and 2000 or exclusively for the Olympic 


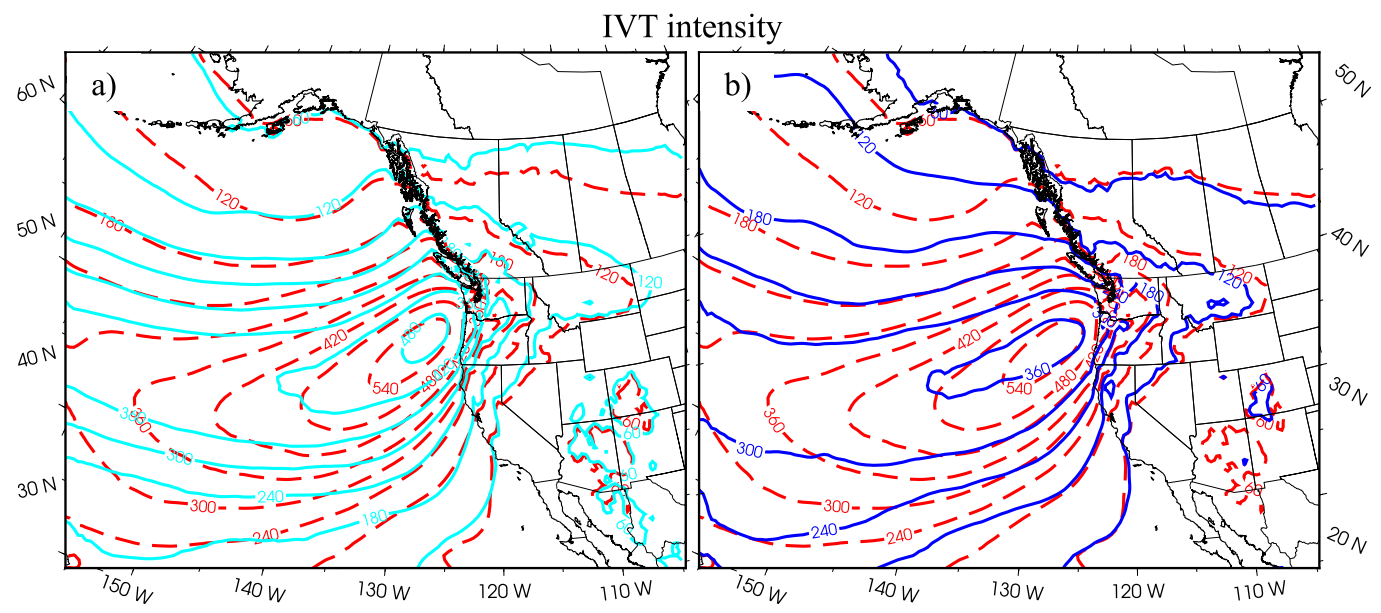

IVT direction

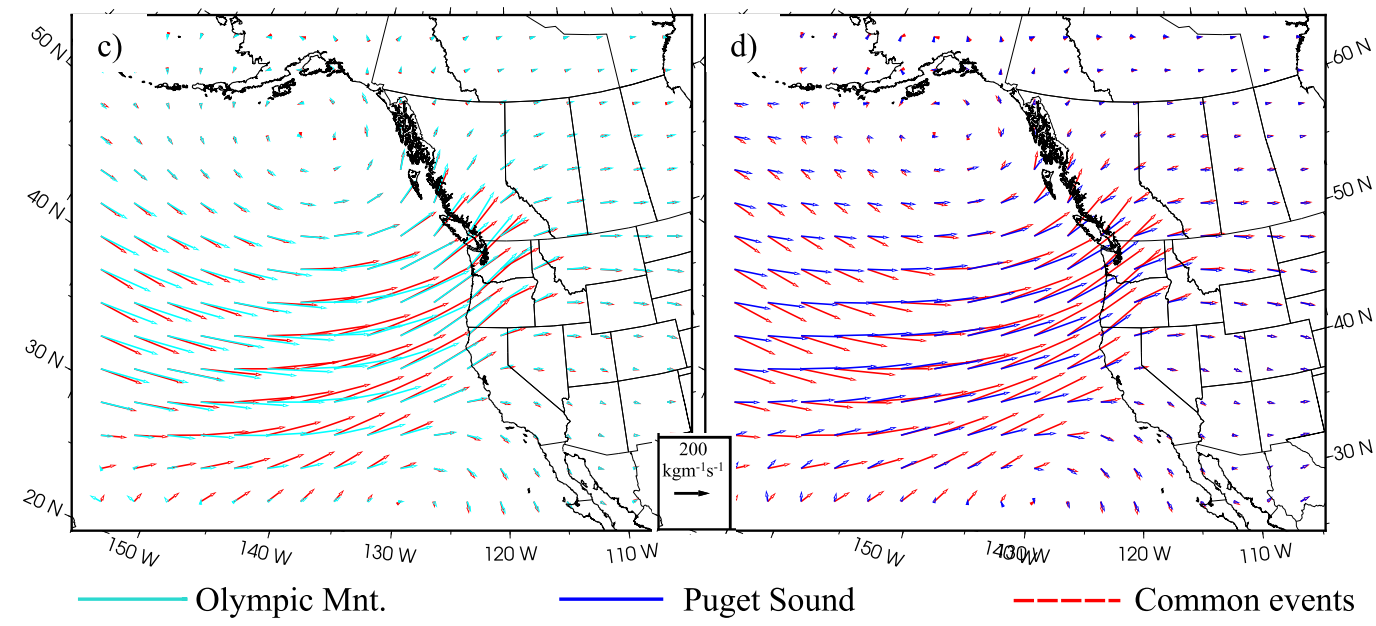

FIG. 6. (a),(b) IVT intensity and (c),(d) IVT direction composites during extreme precipitation events in (left) the Olympics (cyan) and (right) Puget Sound (blue). In all plots, results for the Common events are shown in red.

region during 1985, 1988, and 2004. The maximum number of Common events are simulated for 1982, 1995, and 2003, with more than 10 events in each year. Typically, the Common events produce heavier precipitation than the events exclusive to each region and are more frequent, although this is not true for all years.

The seasonal cycle (for the cool season) of extreme precipitation is shown in Figs. $4 \mathrm{c}$ and $4 \mathrm{~d}$. For the Common events, the occurrence of extreme events increases rapidly from October, reaching a maximum in November and December. The seasonal cycle for the Olympics region is less strong and shifted later in the season, and the cycle for Puget Sound events is even less pronounced. Interestingly, while there is a strong midwinter peak in the frequency of events, the average intensity is not markedly greater during these months, suggesting that the intensity distribution is relatively constant over the season. Overall, events that produce heavy precipitation in both regions produce higher average precipitation intensity and are more frequent than events with heavy precipitation occurring only in one region. Events that occur only for the Olympic Mountains, but not for Puget Sound, are skewed to lower intensity than the Common events, with mean precipitation during extreme events of around $80 \mathrm{~mm} \mathrm{day}^{-1}$ for Common events versus $60 \mathrm{~mm} \mathrm{day}^{-1}$ for exclusive events.

Figures $5 \mathrm{a}-\mathrm{c}$ show average extreme precipitation for Puget Sound, Olympic Mountains, and the events that are common to both regions. The precipitation pattern is similar for Olympic Mountain and Common events, but with overall higher precipitation during Common events. During extreme Puget Sound events, in contrast, the orographic effect of the Olympic Mountains is much weaker than when the extreme events are exclusive to the Olympic region, with substantially less precipitation over the Olympic Peninsula. 

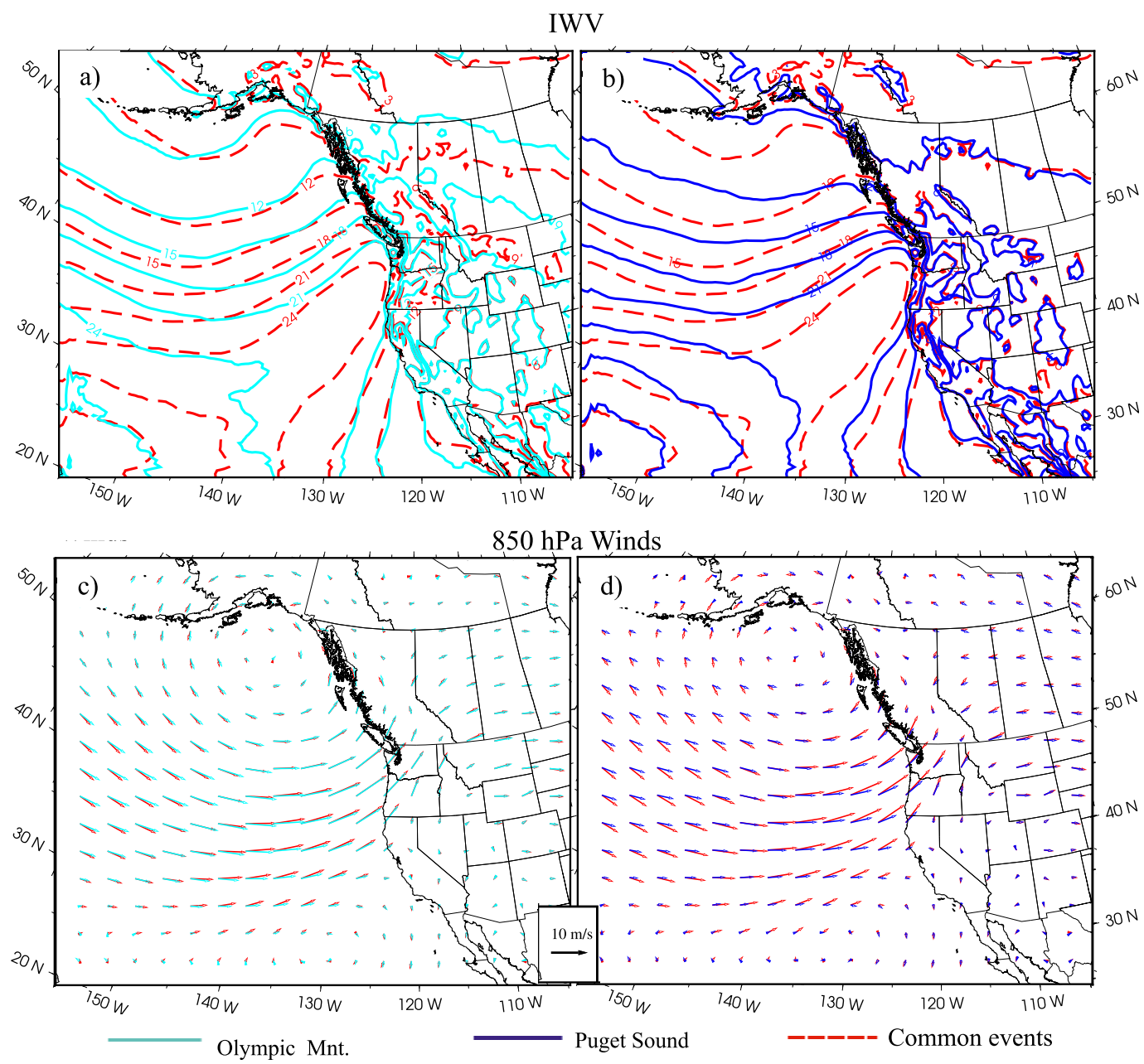

FIG. 7. (a),(b) IWV and (c),(d) 850-hPa wind composites during extreme precipitation events at (left) the Olympic Mountains (cyan) and (right) Puget Sound (blue). In all plots, results for the Common events are shown in red.

Composites of precipitation anomalies are shown in Figs. 5d-f, that is, the percent difference between the mean on extreme precipitation days and the mean over all days. Precipitation anomalies are positive at all locations, indicating that the entire region experiences enhanced precipitation (greater than the climatological mean) when extreme events occur in Puget Sound, the Olympics, or both. During the Common events, precipitation is greater in both regions than if heavy rains occur in just one region.

\section{c. Large-scale drivers of extreme events}

In this section, we analyze the key large-scale drivers associated with Puget Sound and Olympic Mountain events. To do this, the IVT as well as its thermodynamic (IWV) and its dynamic components (winds at $850 \mathrm{hPa}$ ) are inspected.

Figure 6 shows the IVT, computed as in Eq. (2), for days with extreme events in Puget Sound (blue), in
Olympic Mountains (cyan), and in both regions (red). For each set of extreme events, spatial patterns of IVT composites are similar, with larger values between $25^{\circ}$ and $35^{\circ} \mathrm{N}$ latitude, and a maximum close to the coast. Large values of IVT penetrate inland as far east as Montana in all cases.

The largest IVT, in excess of $540 \mathrm{~kg} \mathrm{~m}^{-1} \mathrm{~s}^{-1}$, occurs during Common extreme events (Fig. 6, red), which is approximately $23 \%$ greater than for Puget Sound events $\left(>360 \mathrm{~kg} \mathrm{~m}^{-1} \mathrm{~s}^{-1}\right)$ and $11 \%$ larger than Olympics events $\left(>480 \mathrm{~kg} \mathrm{~m}^{-1} \mathrm{~s}^{-1}\right)$. IVT during Puget Sound events exhibits a weaker latitudinal gradient. High values of IVT originate deeper into the subtropics during the Common events, extending below $30^{\circ} \mathrm{N}$ latitude. This southerly extent of the Common events is made even more clear in the analysis of the IVT vectors (Figs. 6c,d), which show the IVT plume for Common events extends from $25^{\circ} \mathrm{N}$ to the Pacific Northwest, originating in a region of substantially 


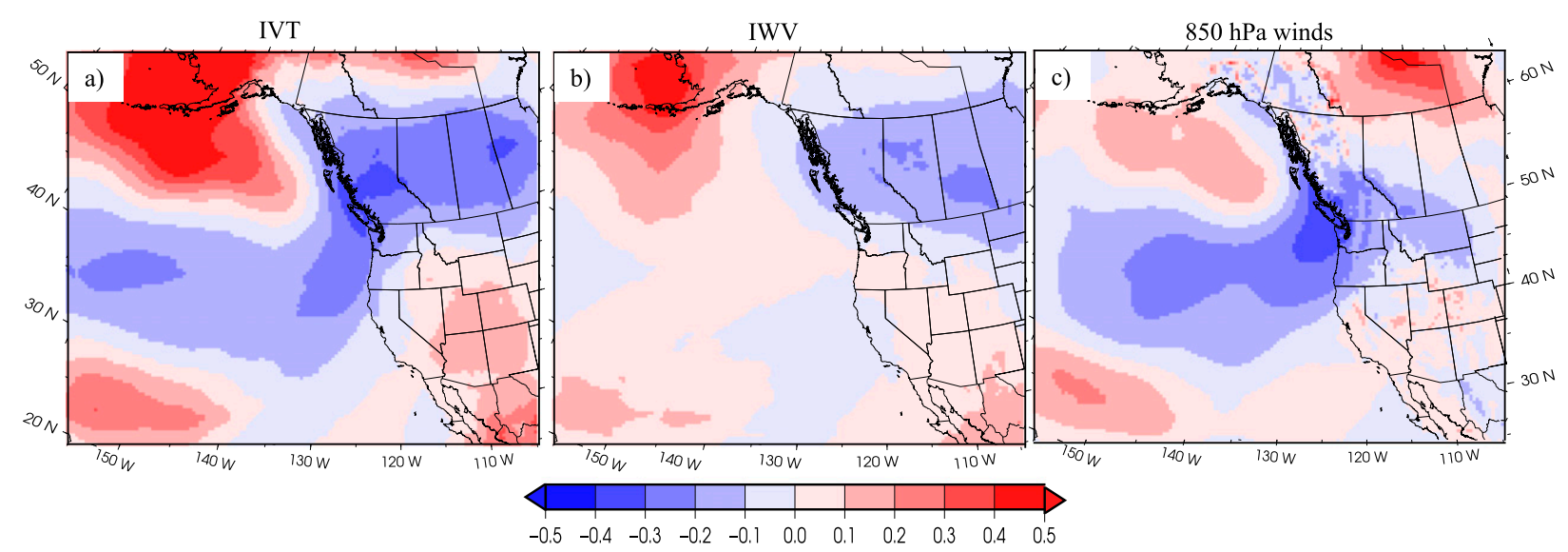

FIG. 8. Normalized Puget Sound minus Olympics events for (a) IVT, (b) IWV, and (c) 850-hPa wind speed.

warmer sea surface temperatures. The Olympics events likewise extend into the subtropics, but not as far. In contrast, the Puget Sound events are associated with a more zonal (westerly) moisture flow across the relatively cooler North Pacific. The more southerly winds for Olympic and Common events than Puget Sound events suggest the transport of warmer air masses during these events is a critical feature.

Composites for extreme events of IWV and the wind components at $850 \mathrm{hPa}$ are analyzed in Fig. 7. IWV patterns are similar for the three cases but are larger in magnitude for the Common extreme events, with a maximum of $24 \mathrm{~kg} \mathrm{~m}^{-2}$. Extreme events at Puget Sound and the Olympics are characterized by similar intensity of IWV with a maximum of $21 \mathrm{~kg} \mathrm{~m}^{-2}$. However, the analysis of $850-\mathrm{hPa}$ winds (Figs. 7c,d) shows significant differences for both direction and intensity for the Puget Sound events compared to events occurring in the Olympics, with weaker and more zonal flow during the Puget Sound events.

To better assess the differences between Olympic and Puget Sound events, Fig. 8 shows the difference maps (Puget Sound minus Olympics) for IVT, IWV, and wind speed at $850 \mathrm{hPa}$. These values are normalized to evaluate if IWV or wind speed differences are larger. IWV is larger over Alaska and the North Pacific during Puget Sound events than during Olympics events, but there are no significant differences where IVT is larger, below $45^{\circ} \mathrm{N}$. In contrast, the anomalies for $850-\mathrm{hPa}$ winds are more distinct. An increase of $48 \%$ can be found close to the coast where IVT has larger values. This suggests that IVT differences between the Olympics and Puget Sound are associated with changes in the dynamic component instead of the thermodynamic component.

To further elucidate differences between the Olympics and Puget Sound events, Fig. 9 shows composites of the anomalies in these same quantities (extreme minus cool season) for IWV and wind speed at $850 \mathrm{hPa}$. On days with heavy precipitation, the IWV and $850-\mathrm{hPa}$ wind speed anomalies are positive close to the IVT maximum. IWV and winds increase during extremes in all three cases of extreme events (Puget Sound, Olympics, and Common events); however, this increase is smaller during Puget Sound events.

Although it appears that winds, and therefore dynamics, are the primary determinant of differences between Puget Sound and Olympics events, it is possible that static stability or wind shear may also play an important role. Figure 10 shows the composites of the anomalies for static stability $\left(\theta_{500}-\theta_{850}\right)$ and wind shear $\left(\mathrm{WS}_{500}-\mathrm{WS}_{850}\right)$. During extreme events, the static stability increases to the north of the IVT maximum and decreases to its south, without changes along the maximum IVT. The anomaly in static stability is more substantial for the Common and Olympic Mountain events than for Puget Sound events. For Puget Sound events, the positive stability anomalies extended farther north, extending over the Puget Sound region. During extreme events, wind shear increases along the core of enhanced IVT, although with less intensity during extreme events in Puget Sound. The increased wind shear may enhance vertical motion and increase convection along the IVT core.

Despite the results that demonstrate that extreme precipitation in the Olympic Mountains and Puget Sound is associated with high values of IVT and IWV, AR definitions also involve other factors such as length and width structure, coherence, persistence, and so on. To inspect if these events correspond to ARs already detected in previous works, the catalog of ARs from the NCEP-NCAR reanalysis computed by Guan and Waliser (2015) is used. The correspondence between these episodes and ARs in Guan's database is larger 

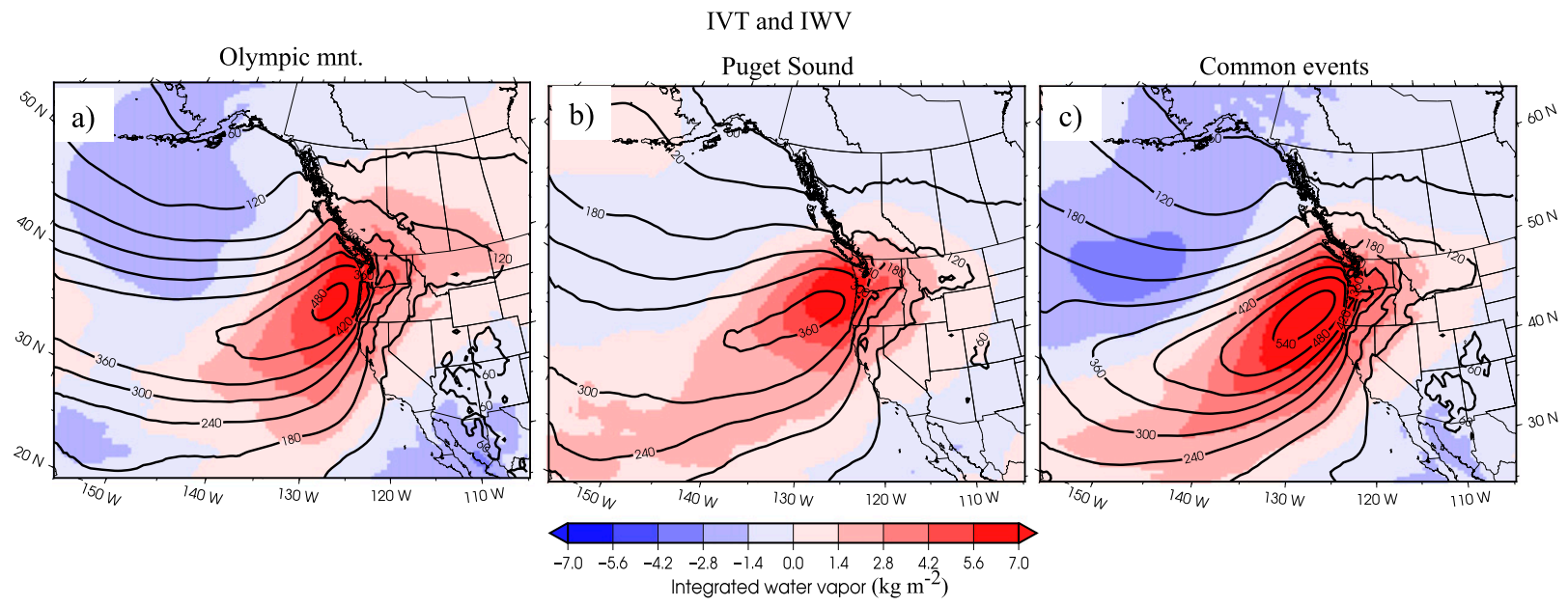

IVT and $850 \mathrm{hPa}$ winds
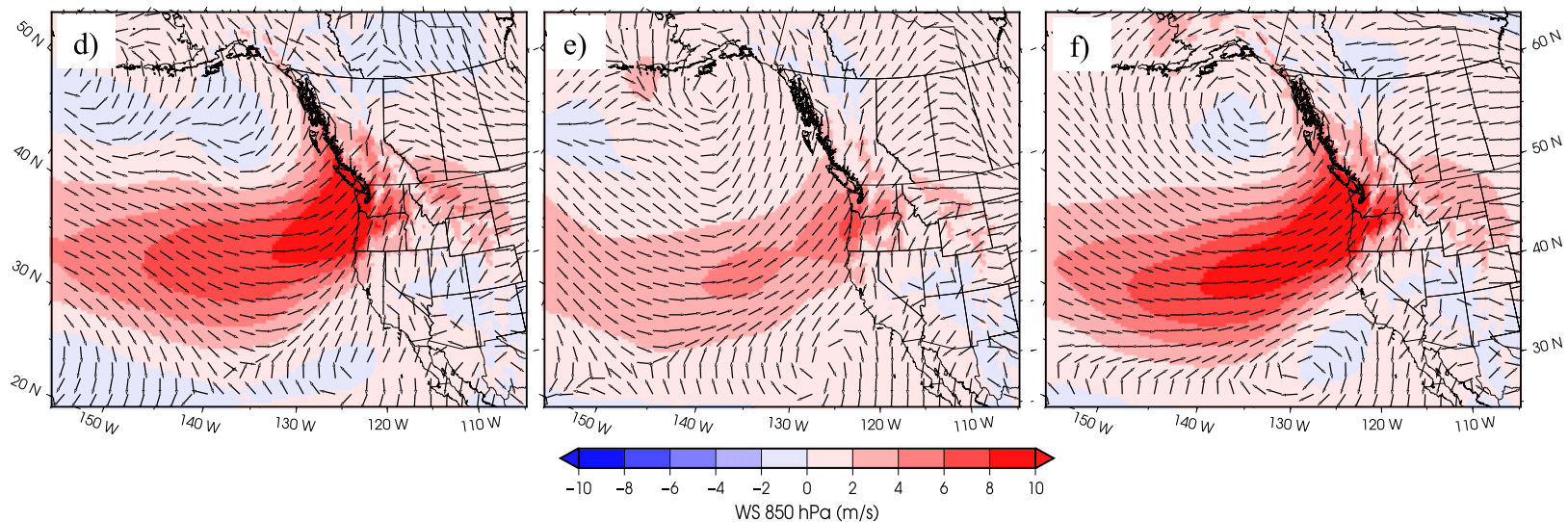

FIG. 9. Shaded (top) IWV and (bottom) 850-hPa wind speed anomalies for (a),(d) Olympics, (b),(e) Puget Sound, and (c),(f) Common events. Black contours depict the IVT intensity in (a)-(c), and black arrows depict the IVT direction in (d)-(f).

than $95 \%$, which supports the relevance of the ARs to extreme precipitation in the target region.

\section{d. Mesoscale effects during extreme precipitation events}

Two specific mesoscale processes could lead to enhanced precipitation over Puget Sound: 1) rain-shadow and 2) convergence zone effects resulting from the Olympic Mountains. To investigate this, we evaluate these events using results from the 12-km WRF domain.

To analyze the rain-shadow effects, the static stability and wind shear are assessed in the higher-resolution domain $(12 \mathrm{~km})$ focusing on the target area. Figure 11 indicates that stability is higher during Puget Sound and Common events as compared to the Olympic Mountain events. As Siler and Durran (2016) have argued, increased stability inhibits descent and therefore adiabatic warming and drying in the lee of the mountains, thereby weakening rain-shadow effects. This same mechanism appears to be at play during the Puget Sound and Common events. In contrast, air is more unstable during Olympics events with warm, moist, and unstable air directed at the terrain. In addition to the stability differences, Puget Sound events have higher wind shear than both the Olympics and Common events (Fig. 11, bottom). Although winds at 850 and $500 \mathrm{hPa}$ are larger during both Olympics and Common events, vertical differences are larger during Puget Sound events because of weaker low-level winds during these events.

Wind shear and stability affect vertical mixing and convection associated with evaporation (from descent) and condensation (from ascent). Figure 12 shows vertical velocity $w$ at 500 and $850 \mathrm{hPa}$. At $850 \mathrm{hPa}$ (Figs. 12d-f), all events show the alternating ascent and descent across the terrain that is described by Siler and Durran (2016), where mountain-wave activity is modulated by subrange-scale ridges and valleys. Specifically, all three 

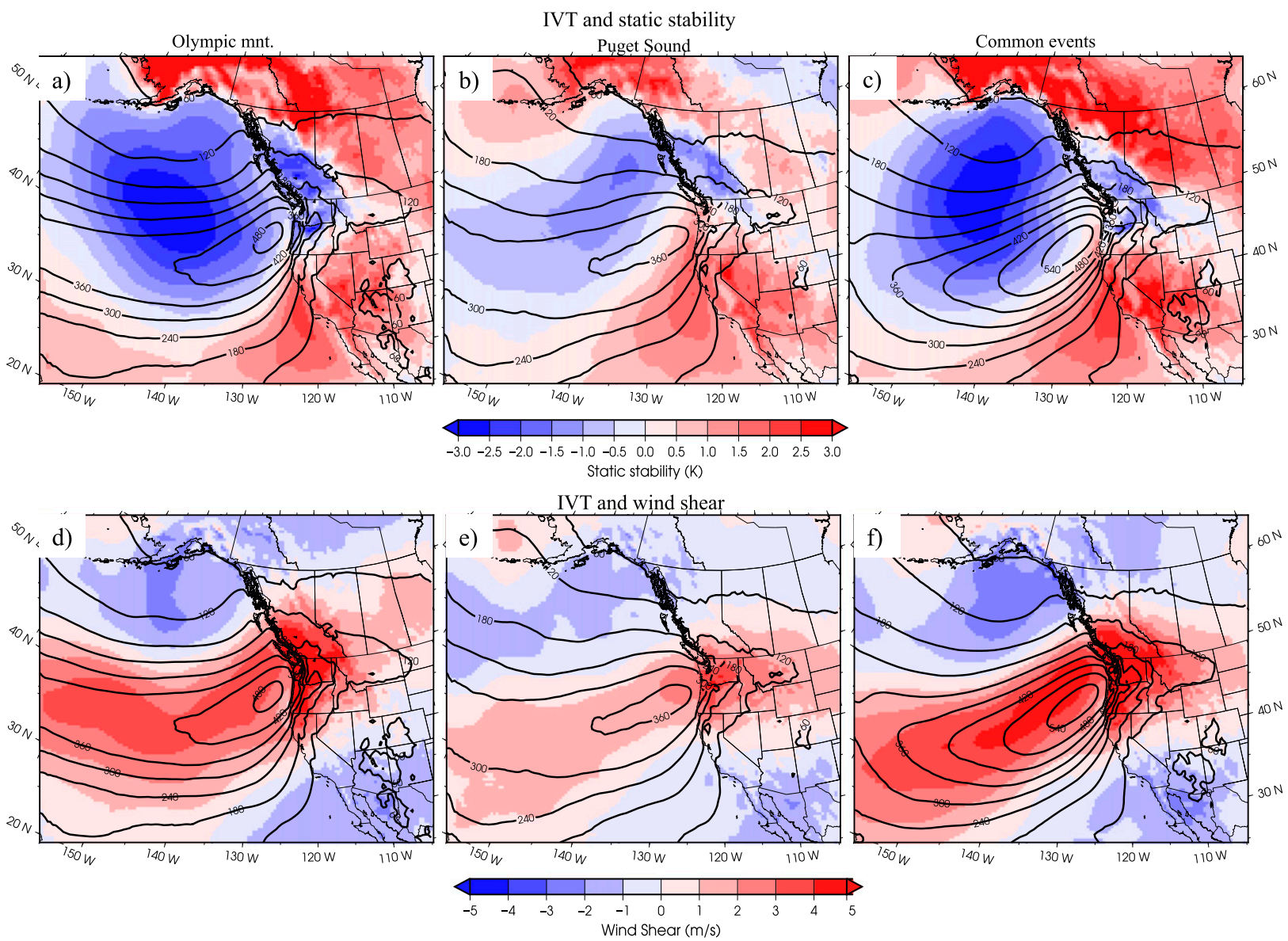

FIG. 10. Shaded (top) static stability and (bottom) wind shear anomalies in the (a),(d) Olympics, (b),(e) Puget Sound, and (c),(f) Common regions. Black contours depict the IVT intensity.

event categories show windward ascent (Fig. 12, orange) and leeside descent (Fig. 12, purple). For the Common events, $w$ shows weaker updrafts and downdrafts.

The 500-hPa vertical velocities analyses (Figs. 12a-c) are similar to those at $850 \mathrm{hPa}$, with two specific exceptions. First, there is a windward shift in the ascent and descent patterns for the Puget Sound, so that the peak rate of descent coincides more closely with the peak of the Olympics, and the maximum rate of ascent coincides with the lee of the mountains. Second, there is weak descent (purple) over nearly the entire domain for the Common events and a small area of weak downward motion over the lee of the Olympics.

During Puget Sound and Olympics events, the flow is more affected by the orography, with weak and strong mountain effects playing a role in the precipitation patterns. During Common events, in contrast, the effect of topography appears to be much weaker, suggesting that large-scale precipitation could be more important than convective precipitation during these events. The results for static stability and wind shear support this interpretation (Fig. 11). Vertical movements at Puget Sound are more forced by wind shear than by instabilities; meanwhile, for Olympics mountains events, vertical motions are due to static instabilities. In contrast, low shear and the strong stability during Common events weaken the vertical movements in the target area.

To test the hypothesis that large-scale precipitation plays a key role in the Common events, Fig. 13 compares the simulated nonconvective precipitation (Figs. 13a-c) and convective precipitation (Figs. 13d-f). Nonconvective precipitation is precipitation due to the resolved motions in the WRF model, while convective precipitation is produced by the convective parameterization. In general, nonconvective precipitation is much larger (around an order of magnitude) than convective precipitation; note the different scale range. Comparing Common and Olympics events, we find that nonconvective precipitation is more important for the Common events, while convective precipitation is more important for the Olympics events. Likewise, during Puget Sound events, nonconvective precipitation extends into the 

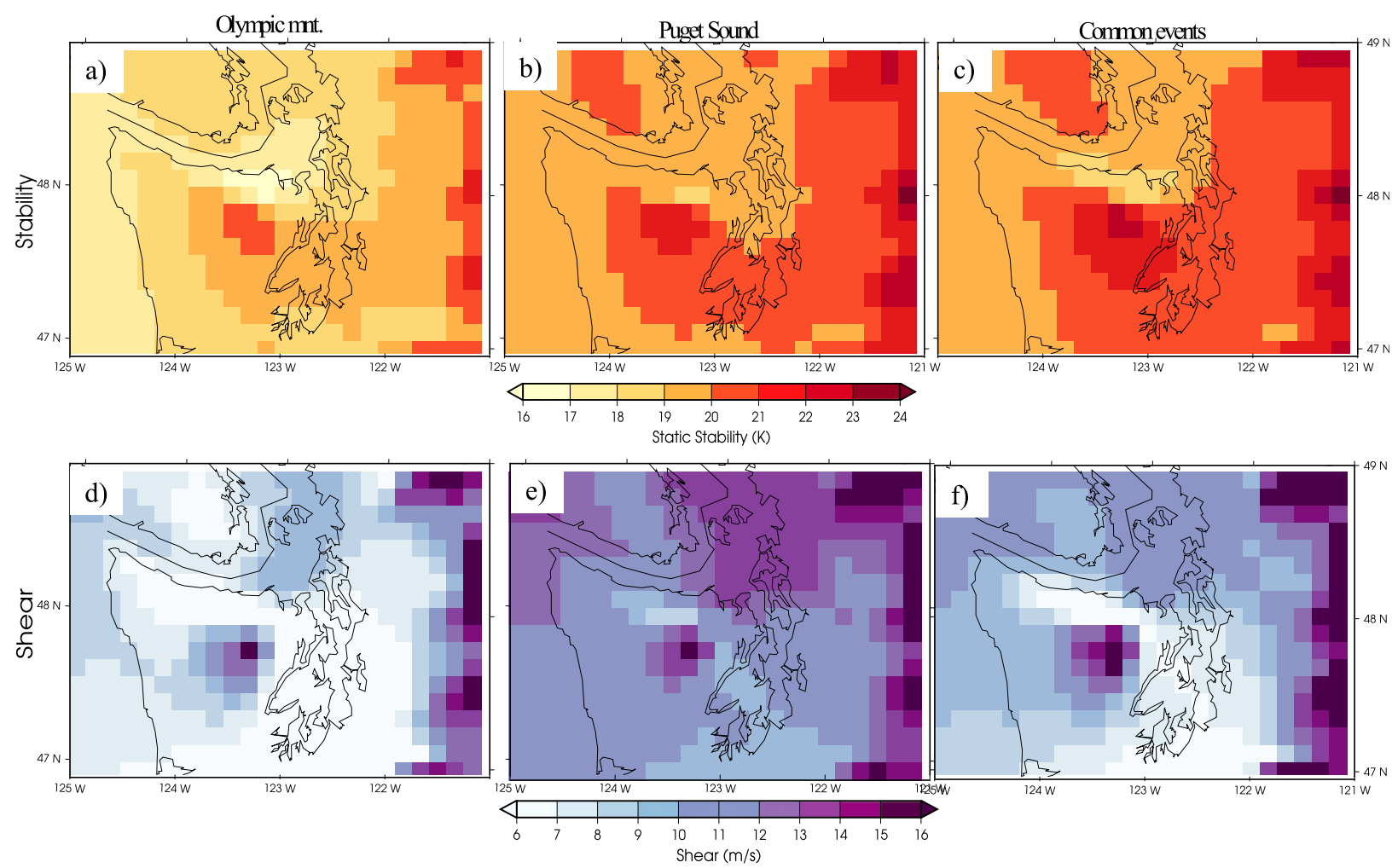

FIG. 11. (top) Static stability and (bottom) wind shear in the (a),(d) Olympics, (b),(e) Puget Sound, and (c),(f) Common regions using the higher-resolution simulation over western Washington State (white rectangle in Fig. 2b).

lee of the Olympics without a strong rain shadow. In all cases, convective precipitation shows a stronger rain shadow than nonconvective precipitation. This result suggests that large-scale motions, resolved by the model at 12-km grid spacing, account for most of the precipitation in Common events, while unresolved processes, captured by the convective parameterization, are critical for the Olympics events.

A second possibility is that the Puget Sound events are "convergence zone events," in which precipitation is enhanced in the lee of the Olympics because of the convergence of flows that are bifurcated by the Olympic Mountains. Figure 14 examines the horizontal winds at 850 and $500 \mathrm{hPa}$ for the three regions (Puget Sound, Olympics, and both) using results from the 12-km WRF. The more westerly flow for the Puget Sound events is consistent with observed incidences of convergence zone events (Mass 1981). But, these events would have lower stability due to the convergence that is not in agreement with Fig. 11. Although there may nonetheless be some convection driven by downstream flow convergence, the results suggest that a weak rain shadow is the dominant feature of extreme events unique to the Puget Sound region.

The analysis of the wind direction at 850 and $500 \mathrm{hPa}$ (Fig. 14) also helps to illustrate its role in regulating the strength of the rain shadow. As is expected, the larger differences between 850 - and $500-\mathrm{hPa}$ winds are found over land, where $850-\mathrm{hPa}$ winds are more braked by the orography. During Puget Sound events, veering with the height is negligible, but the orographic drag turns 850-hPa winds clockwise, becoming less westerly during Olympics and Common events. According to Mass et al. (2015), with stronger warm-air advection, weakshadow storms exhibit more veering of winds with height, minimizing the influence of the mountains altogether such that condensation and precipitation are essentially governed by large-scale dynamics. This could be the mechanism that dominates during Common extreme events.

In summary, there are three different situations that drive regional distinctions in extreme precipitation: 1 ) weak shadowing during Puget Sound events, 2) strong rain shadowing during Olympics events, and 3) interplays between large-scale ascent and orographic effects during Common extreme events.

\section{Conclusions}

Using cluster analysis, we find that daily precipitation in the Pacific Northwest is characterized by many small 

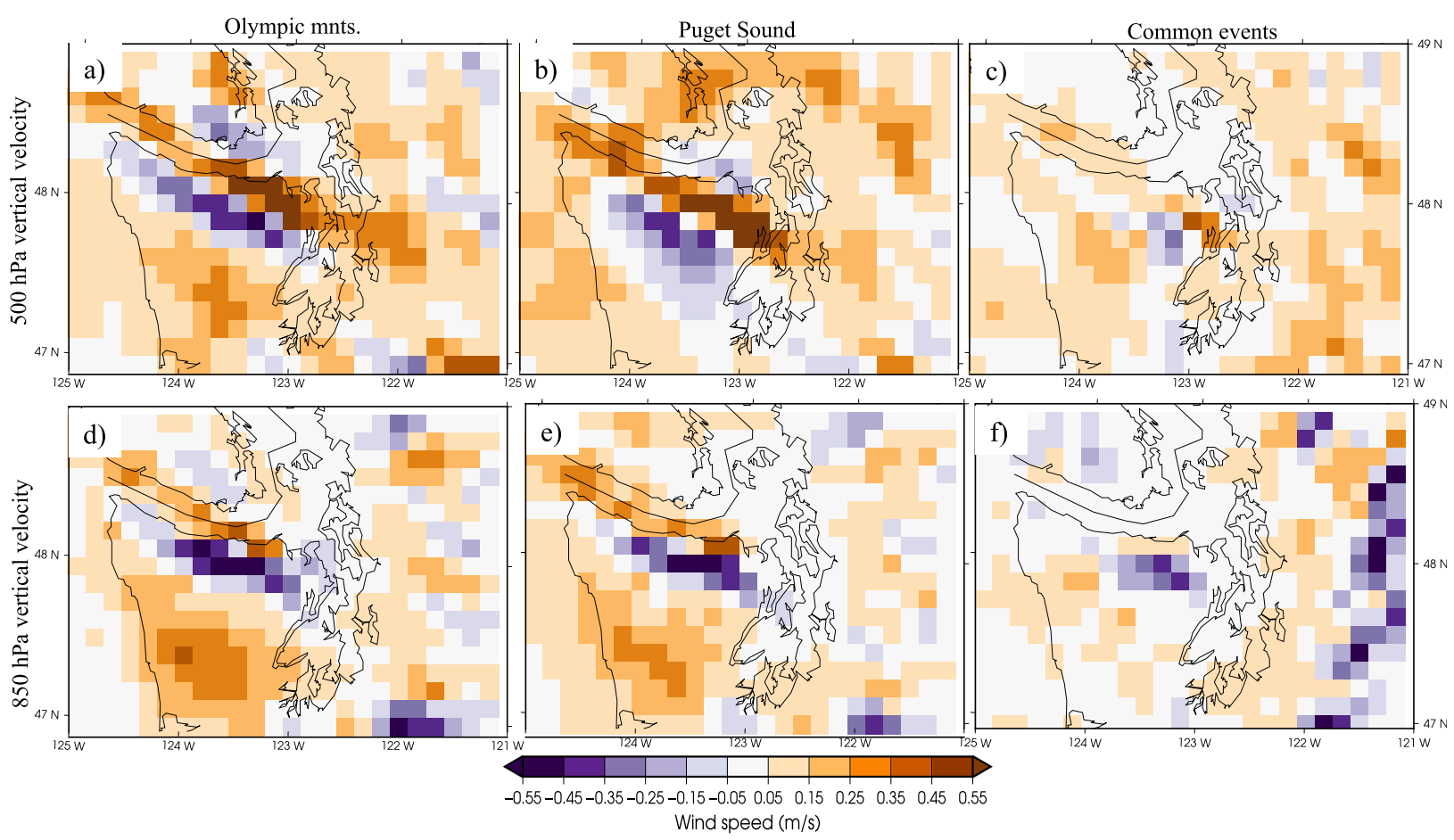

FIG. 12. Vertical velocity at (top) 500 and (bottom) $850 \mathrm{hPa}$ for (a),(d) Olympics, (b),(e) Puget Sound, and (c),(f) Common events.

regions of coherent variability. These regions reflect both a primary north-south clustering that is revealed with a small number of clusters, while a larger number of clusters shows a disaggregation of these regions around the terrain. In particular, precipitation between the windward and lee slopes of mountain ranges have different modes of variability, as illustrated by the distinct precipitation variability found on the west slopes of the Olympics and interior Puget Sound.

For strong precipitation events (top 5\% of daily coolseason events) over the Olympic Mountain and Puget Sound regions, approximately two-thirds occur simultaneously while one-third are unique to each region. Although substantial research has been devoted to understanding the mechanisms driving the incidence of atmospheric rivers in the region, relatively little is known about what makes these events different for specific parts of the Pacific Northwest.

The Common events are associated with very strong atmospheric river patterns with deep offshore troughing and substantial integrated water vapor transport extending from the subtropical Pacific to the Pacific Northwest.

Olympic Mountain events are similar to the Common events, sharing the atmospheric river structure, but with a less pronounced trough on average, lower levels of IVT, and a stronger rain shadowing. These events show more pronounced static instability than the Common events, which are fairly neutral. Such conditions favor strong rain shadows, with uplift and descent following the terrain.

Puget Sound events have more zonal flow and higher static stability than the Common events. These results suggest two mechanisms for increased heavy precipitation in the Puget Sound region: 1) increased stability over the Puget Sound region, allowing largescale uplift to persist in the lee of the Olympics (Siler and Durran 2016; 2) the westerly flow permitting greater moisture transport through the terrain gaps north and south of the Olympic Mountains, supplying precipitation in the region, potentially with a Puget Sound convergence zone (Mass 1981). While the first mechanism is more consistent with our analysis, it is possible that both sorts of events are found in this category.

Column-integrated water vapor over the region is comparable for all events, but the wind fields differ substantially, indicating that the circulation pattern, not thermodynamics, determines the differences between these events. This result has important implications for climate change projections since it complicates the simple argument that climate change yields a direct $7 \%$ increase in heavy precipitation per degree of 

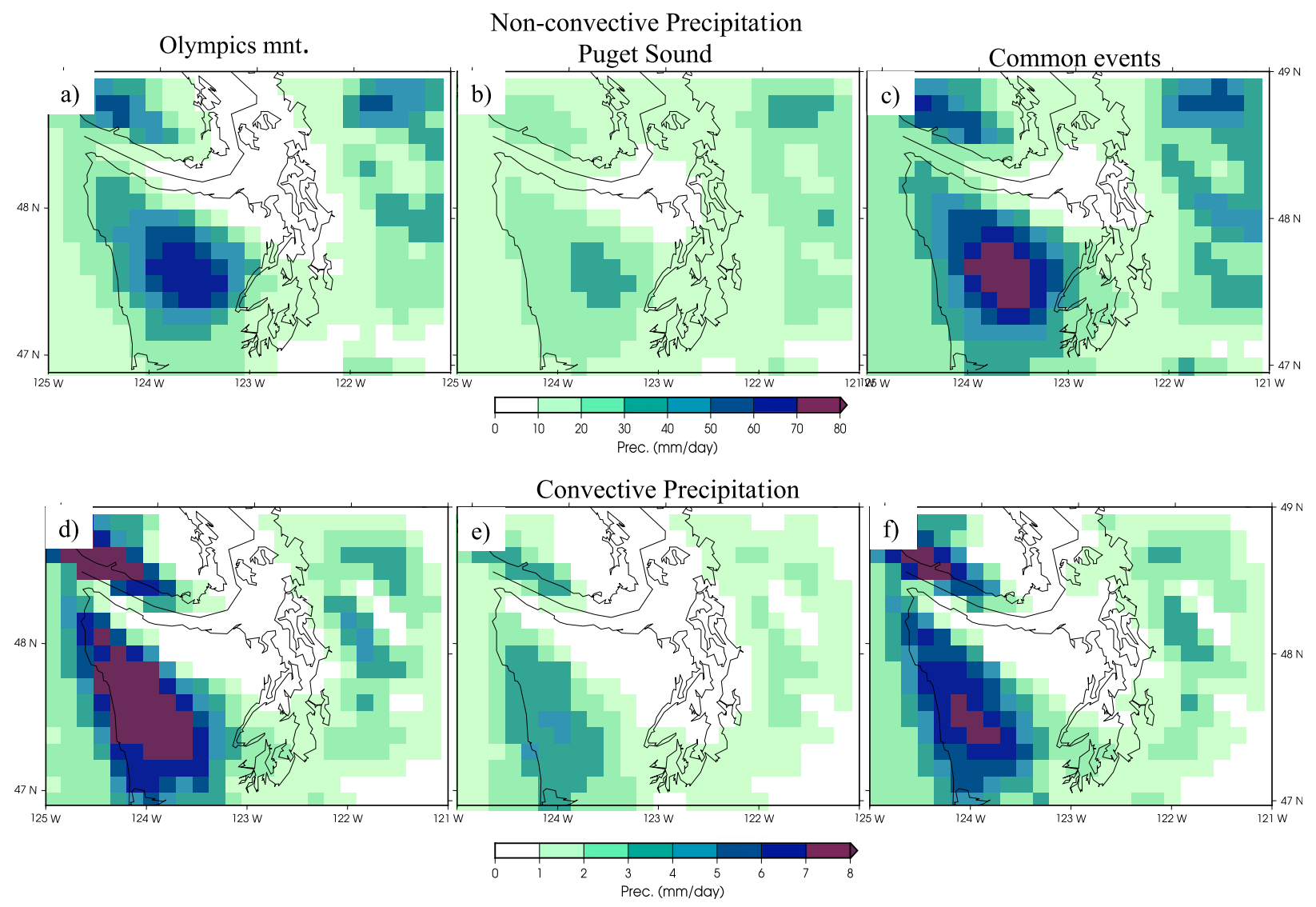

FIG. 13. (top) Nonconvective precipitation and (bottom) convective precipitation during (a),(d) Olympics, (b),(e) Puget Sound, and (c),(f) Common events.

warming (due to the Clausius-Clapeyron relationship between temperature and saturation vapor pressure). For regions on the spatial scale identified in this paper, subtle changes in circulation patterns over the northeast Pacific could result in important localized deviations from this scaling if future weather patterns are more or less conducive to heavy precipitation in a specific region. We explore this possibility in future work based on the cluster analysis applied to climate change simulations.
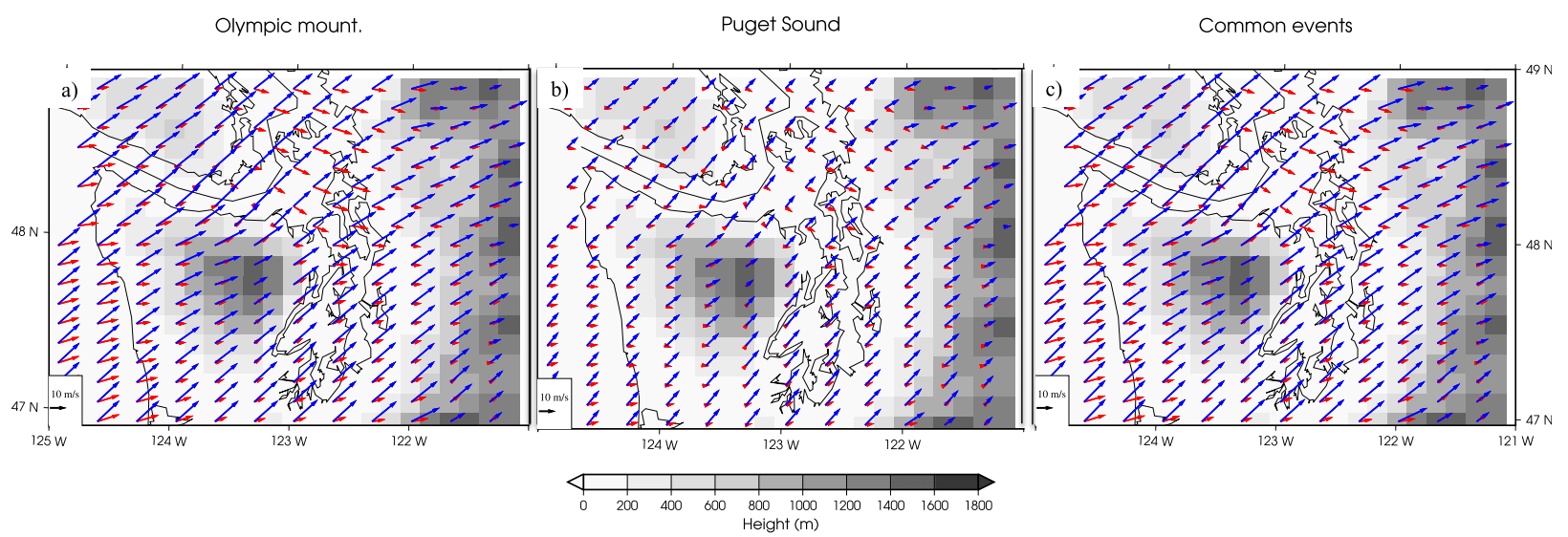

FIG. 14. Wind direction at 850 (red) and $500 \mathrm{hPa}$ (blue) during (a) Olympics, (b) Puget Sound, and (c) Common events. Gray shading shows the modeled orography. 
Acknowledgments. This work was funded under a subcontract (2015-ST-061-CIRC01) from Critical Infrastructure Resilience Institute (CIRI), a U.S. Department of Homeland Security S\&T Center of Excellence led by the University of Illinois at Urbana-Champaign. This research was also partially supported by the Washington State Department of Ecology, and the Water and Land Resources and Wastewater Treatment Divisions within King County's Department of Natural Resources and Parks. The authors also thank Rick Steed for his collaboration performing the regional climate simulations. Raquel Lorente-Plazas also acknowledges the Contrato postdoctoral de reincorporacion by the University of Murcia.

\section{REFERENCES}

Allan, R. P., and B. J. Soden, 2008: Atmospheric warming and the amplification of precipitation extremes. Science, 321, 14811484, https://doi.org/10.1126/science.1160787.

Allen, M. R., and W. J. Ingram, 2002: Constraints on future changes in climate and the hydrologic cycle. Nature, 419, 224-232, https://doi.org/10.1038/nature01092.

Cattell, R., 1966: The scree test for the number of factors. Multivar. Behav. Res., 1, 245-276, https://doi.org/10.1207/s15327906mbr0102_10.

Chen, F., and J. Dudhia, 2001: Coupling an advanced land surface-hydrology model with the Penn State-NCAR MM5 modeling system. Part I: Model implementation and sensitivity. Mon. Wea. Rev., 129, 569-586, https://doi.org/10.1175/ 1520-0493(2001)129<0569:CAALSH > 2.0.CO;2.

Dettinger, M., 2011: Climate change, atmospheric rivers, and floods in California-A multimodel analysis of storm frequency and magnitude changes. J. Amer. Water Resour. Assoc., 47, 514523, https://doi.org/10.1111/j.1752-1688.2011.00546.x.

Di Luca, A., R. de Elía, and R. Laprise, 2012: Potential for added value in precipitation simulated by high-resolution nested regional climate models and observations. Climate Dyn., $\mathbf{3 8}$, 1229-1247, https://doi.org/10.1007/s00382-011-1068-3.

Dulière, V., Y. Zhang, and E. P. Salathé Jr., 2011: Extreme precipitation and temperature over the U.S. Pacific Northwest: A comparison between observations, reanalysis data, and regional models. J. Climate, 24, 1950-1964, https://doi.org/ 10.1175/2010JCLI3224.1.

Eiras-Barca, J., S. Brands, and G. Miguez-Macho, 2016: Seasonal variations in North Atlantic atmospheric river activity and associations with anomalous precipitation over the Iberian Atlantic margin. J. Geophys. Res. Atmos., 121, 931-948, https://doi.org/10.1002/2015JD023379.

—_, F. Dominguez, H. Hu, D. Garaboa-Paz, and G. MiguezMacho, 2017: Evaluation of the moisture sources in two extreme landfalling atmospheric river events using an Eulerian WRF tracers tool. Earth Syst. Dyn., 8, 1247-1261, https://doi.org/10.5194/esd-8-1247-2017.

Feser, F., B. Rockel, H. von Storch, J. Winterfeldt, and M. Zahn, 2011: Regional climate models add value to global model data: A review and selected examples. Bull. Amer. Meteor. Soc., 92, 1181-1192, https://doi.org/10.1175/2011BAMS3061.1.

Gimeno, L., R. Nieto, M. Vázquez, and D. Lavers, 2014: Atmospheric rivers: A mini-review. Front. Earth Sci., 2, 2, https:// doi.org/10.3389/feart.2014.00002.
Guan, B., and D. E. Waliser, 2015: Detection of atmospheric rivers: Evaluation and application of an algorithm for global studies. J. Geophys. Res. Atmos., 120, 12 514-12 535, https://doi.org/ 10.1002/2015JD024257.

Held, I. M., and B. J. Soden, 2006: Robust responses of the hydrological cycle to global warming. J. Climate, 19, 5686-5699, https://doi.org/10.1175/JCLI3990.1.

Hong, S.-Y., Y. Noh, and J. Dudhia, 2006: A new vertical diffusion package with an explicit treatment of entrainment processes. Mon. Wea. Rev., 134, 2318-2341, https://doi.org/10.1175/ MWR3199.1.

Jiménez, P., E. García-Bustamante, J. González-Rouco, F. Valero, J. Montávez, and J. Navarro, 2008: Surface wind regionalization in complex terrain. J. Appl. Meteor. Climatol., 47, 308-325, https:// doi.org/10.1175/2007JAMC1483.1.

_ J. Judhia, J. F. González-Rouco, J. Navarro, J. P. Montávez, and E. García-Bustamante, 2012: A revised scheme for the WRF surface layer formulation. Mon. Wea. Rev., 140, 898918, https://doi.org/10.1175/MWR-D-11-00056.1.

Kain, J. S., 2004: The Kain-Fritsch convective parameterization: An update. J. Appl. Meteor., 43, 170-181, https://doi.org/ 10.1175/1520-0450(2004)043<0170:TKCPAU > 2.0.CO;2.

Kalnay, E., and Coauthors, 1996: The NCEP/NCAR 40-Year Reanalysis Project. Bull. Amer. Meteor. Soc., 77, 437-471, https:// doi.org/10.1175/1520-0477(1996)077<0437:TNYRP>2.0.CO;2.

Kamae, Y., W. Mei, S.-P. Xie, M. Naoi, and H. Ueda, 2017: Atmospheric rivers over the northwestern Pacific: Climatology and interannual variability. J. Climate, 30, 5605-5619, https:// doi.org/10.1175/JCLI-D-16-0875.1.

Kaufmann, P., and R. Weber, 1996: Classification of mesoscale wind fields in the MISTRAL field experiment. J. Appl. Meteor., 35, 1963-1979, https://doi.org/10.1175/1520-0450(1996) 035<1963:COMWFI>2.0.CO;2.

Kirshbaum, D. J., and D. R. Durran, 2004: Factors governing cellular convection in orographic precipitation. J. Atmos. Sci., 61, 682-698, https://doi.org/10.1175/1520-0469(2004) 061<0682:FGCCIO>2.0.CO;2.

Lavers, D. A., and G. Villarini, 2013: The nexus between atmospheric rivers and extreme precipitation across Europe. Geophys. Res. Lett., 40, 3259-3264, https://doi.org/10.1002/grl.50636.

Lorente-Plazas, R., J. Montávez, P. Jimenez, S. Jerez, J. GómezNavarro, J. García-Valero, and P. Jimenez-Guerrero, 2015: Characterization of surface winds over the Iberian Peninsula. Int. J. Climatol., 35, 1007-1026, https://doi.org/10.1002/joc.4034.

Mass, C., 1981: Topographically forced convergence in western Washington State. Mon. Wea. Rev., 109, 1335-1347, https:// doi.org/10.1175/1520-0493(1981)109<1335:TFCIWW>2.0.CO;2.

_, N. Johnson, M. Warner, and R. Vargas, 2015: Synoptic control of cross-barrier precipitation ratios for the Cascade Mountains. J. Hydrometeor., 16, 1014-1028, https://doi.org/ 10.1175/JHM-D-14-0149.1.

Minder, J. R., T. W. Letcher, and C. Liu, 2018: The character and causes of elevation-dependent warming in high-resolution simulations of Rocky Mountain climate change. J. Climate, 31, 2093-2113, https://doi.org/10.1175/JCLI-D-17-0321.1.

Mlawer, E. J., S. J. Taubman, P. D. Brown, M. J. Iacono, and S. A. Clough, 1997: Radiative transfer for inhomogeneous atmospheres: RRTM, a validated correlated-k model for the longwave. J. Geophys. Res., 102, 16 663-16 682, https://doi.org/ 10.1029/97JD00237.

Neiman, P. J., F. M. Ralph, G. A. Wick, Y.-H. Kuo, T.-K. Wee, Z. Ma, G. H. Taylor, and M. D. Dettinger, 2008: Diagnosis of an intense atmospheric river impacting the Pacific Northwest: 
Storm summary and offshore vertical structure observed with COSMIC satellite retrievals. Mon. Wea. Rev., 136, 4398-4420, https://doi.org/10.1175/2008MWR2550.1.

— L. J. Schick, F. M. Ralph, M. Hughes, and G. A. Wick, 2011: Flooding in western Washington: The connection to atmospheric rivers. J. Hydrometeor., 12, 1337-1358, https://doi.org/ 10.1175/2011JHM1358.1.

O'Gorman, P. A., and T. Schneider, 2009: The physical basis for increases in precipitation extremes in simulations of 21stcentury climate change. Proc. Natl. Acad. Sci. USA, 106, 14 773-14 777, https://doi.org/10.1073/pnas.0907610106.

Paltan, H., D. Waliser, W. H. Lim, B. Guan, D. Yamazaki, R. Pant, and S. Dadson, 2017: Global floods and water availability driven by atmospheric rivers. Geophys. Res. Lett., 44, $10387-$ 10395, https://doi.org/10.1002/2017GL074882.

Peterson, T. C., X. Zhang, M. Brunet-India, and J. L. VázquezAguirre, 2008: Changes in North American extremes derived from daily weather data. J. Geophys. Res., 113, D07113, https://doi.org/10.1029/2007JD009453.

Ralph, F. M., P. J. Neiman, and R. Rotunno, 2005: Dropsonde observations in low-level jets over the northeastern Pacific Ocean from CALJET-1998 and PACJET-2001: Mean vertical-profile and atmospheric-river characteristics. Mon. Wea. Rev., 133, 889-910, https://doi.org/10.1175/MWR2896.1. , - - G. A. Wick, S. I. Gutman, M. D. Dettinger, D. R. Cayan, and A. B. White, 2006: Flooding on California's Russian River: Role of atmospheric rivers. Geophys. Res. Lett., 33, L13801, https://doi.org/10.1029/2006GL026689.

, E. Sukovich, D. Reynolds, M. Dettinger, S. Weagle, W. Clark, and P. J. Neiman, 2010: Assessment of extreme quantitative precipitation forecasts and development of regional extreme event thresholds using data from HMT-2006 and COOP observers. J. Hydrometeor., 11, 1286-1304, https:// doi.org/10.1175/2010JHM1232.1.

, T. Coleman, P. J. Neiman, R. J. Zamora, and M. D. Dettinger, 2013: Observed impacts of duration and seasonality of atmospheric-river landfalls on soil moisture and runoff in coastal Northern California. J. Hydrometeor., 14, 443-459, https://doi.org/10.1175/JHM-D-12-076.1.

—_, and Coauthors, 2016: CalWater field studies designed to quantify the roles of atmospheric rivers and aerosols in modulating U.S. West Coast precipitation in a changing climate. Bull. Amer. Meteor. Soc., 97, 1209-1228, https://doi.org/ 10.1175/BAMS-D-14-00043.1.

Ramos, A. M., R. M. Trigo, M. L. R. Liberato, and R. Tomé, 2015: Daily precipitation extreme events in the Iberian Peninsula and its association with atmospheric rivers. J. Hydrometeor., 16, 579-597, https://doi.org/10.1175/JHM-D-14-0103.1.

Rasmussen, R., and Coauthors, 2014: Climate change impacts on the water balance of the Colorado Headwaters: High-resolution regional climate model simulations. J. Hydrometeor., 15, 10911116, https://doi.org/10.1175/JHM-D-13-0118.1.

Richman, M. B., 1986: Rotation of principal components. Int. J. Climatol., 6, 293-335, https://doi.org/10.1002/joc.3370060305.

Siler, N., and D. Durran, 2016: What causes weak orographic rain shadows? Insights from case studies in the Cascades and idealized simulations. J. Atmos. Sci., 73, 4077-4099, https://doi.org/ 10.1175/JAS-D-15-0371.1.
- G. Roe, and D. Durran, 2013: On the dynamical causes of variability in the rain-shadow effect: A case study of the Washington Cascades. J. Hydrometeor., 14, 122-139, https:// doi.org/10.1175/JHM-D-12-045.1.

Skamarock, W. C., and Coauthors, 2008: A description of the Advanced Research WRF version 3. NCAR Tech. Note NCAR/ TN-475+STR, 113 pp., https://doi.org/10.5065/D68S4MVH.

Sodemann, H., and A. Stohl, 2013: Moisture origin and meridional transport in atmospheric rivers and their association with multiple cyclones. Mon. Wea. Rev., 141, 2850-2868, https:// doi.org/10.1175/MWR-D-12-00256.1.

Stohl, A., C. Forster, and H. Sodemann, 2008: Remote sources of water vapor forming precipitation on the Norwegian west coast at $60^{\circ} \mathrm{N}-\mathrm{A}$ tale of hurricanes and an atmospheric river. J. Geophys. Res., 113, D05102, https://doi.org/10.1029/ 2007JD009006.

Thompson, G., P. R. Field, R. M. Rasmussen, and W. D. Hall, 2008: Explicit forecasts of winter precipitation using an improved bulk microphysics scheme. Part II: Implementation of a new snow parameterization. Mon. Wea. Rev., 136, 5095-5115, https://doi.org/10.1175/2008MWR2387.1.

Trenberth, K. E., A. Dai, R. M. Rasmussen, and D. B. Parsons, 2003: The changing character of precipitation. Bull. Amer. Meteor. Soc., 84, 1205-1217, https://doi.org/10.1175/BAMS84-9-1205.

Van den Dool, H., S. Saha, and A. Johansson, 2000: Empirical orthogonal teleconnections. J. Climate, 13, 1421-1435, https:// doi.org/10.1175/1520-0442(2000)013<1421:EOT>2.0.CO;2.

Viale, M., and M. N. Nuñez, 2011: Climatology of winter orographic precipitation over the subtropical central Andes and associated synoptic and regional characteristics. J. Hydrometeor., 12, 481507, https://doi.org/10.1175/2010JHM1284.1.

von Storch, H., and F. Zwiers, 1999: Statistical Analysis in Climate Research. Cambridge University Press, 499 pp.

Ward, J. H., Jr., 1963: Hierarchical grouping to optimize an objective function. J. Amer. Stat. Assoc., 58, 236-244, https:// doi.org/10.1080/01621459.1963.10500845.

Warner, M. D., C. F. Mass, and E. P. Salathé Jr., 2015: Changes in winter atmospheric rivers along the North American West Coast in CMIP5 climate models. J. Hydrometeor., 16, 118-128, https://doi.org/10.1175/JHM-D-14-0080.1.

Wick, G. A., P. J. Neiman, and F. M. Ralph, 2013a: Description and validation of an automated objective technique for identification and characterization of the integrated water vapor signature of atmospheric rivers. IEEE Trans. Geosci. Remote Sens., 51, 2166-2176, https://doi.org/10.1109/TGRS.2012.2211024.

,,,--- and T. M. Hamill, 2013b: Evaluation of forecasts of the water vapor signature of atmospheric rivers in operational numerical weather prediction models. Wea. Forecasting, 28, 1337-1352, https://doi.org/10.1175/WAF-D-13-00025.1.

Wilks, D., 1995: Statistical Methods in the Atmospheric Sciences: An Introduction. International Geophysics Series, Vol. 59, Elsevier, 467 pp.

Zhu, Y., and R. E. Newell, 1998: A proposed algorithm for moisture fluxes from atmospheric rivers. Mon. Wea. Rev., 126, 725-735, https://doi.org/10.1175/1520-0493(1998)126<0725: APAFMF $>2.0 . \mathrm{CO} ; 2$. 